\title{
Running on Empty: Abandoned Churches in Downtown Kitchener
}

\author{
by \\ Zabdi Falcon
}

A thesis submitted to the Faculty of Graduate and Postdoctoral Affairs in partial fulfillment of the requirements for the degree of

Master

in

Architecture

Carleton University

Ottawa, Ontario

(C)2019

Zabdi Falcon 
To my advisors, Roger Connah and Yvan Cazabon for their patience and trust. To Ajon Moriyama for all your encouragement and input.

To Lucas for your constant support.

To my dear family for their unending love and support. To my parents for their inspiring and comforting words and their daily wisdom. To my sisters for their faith in me and the incredible examples they have set.

Thank you.

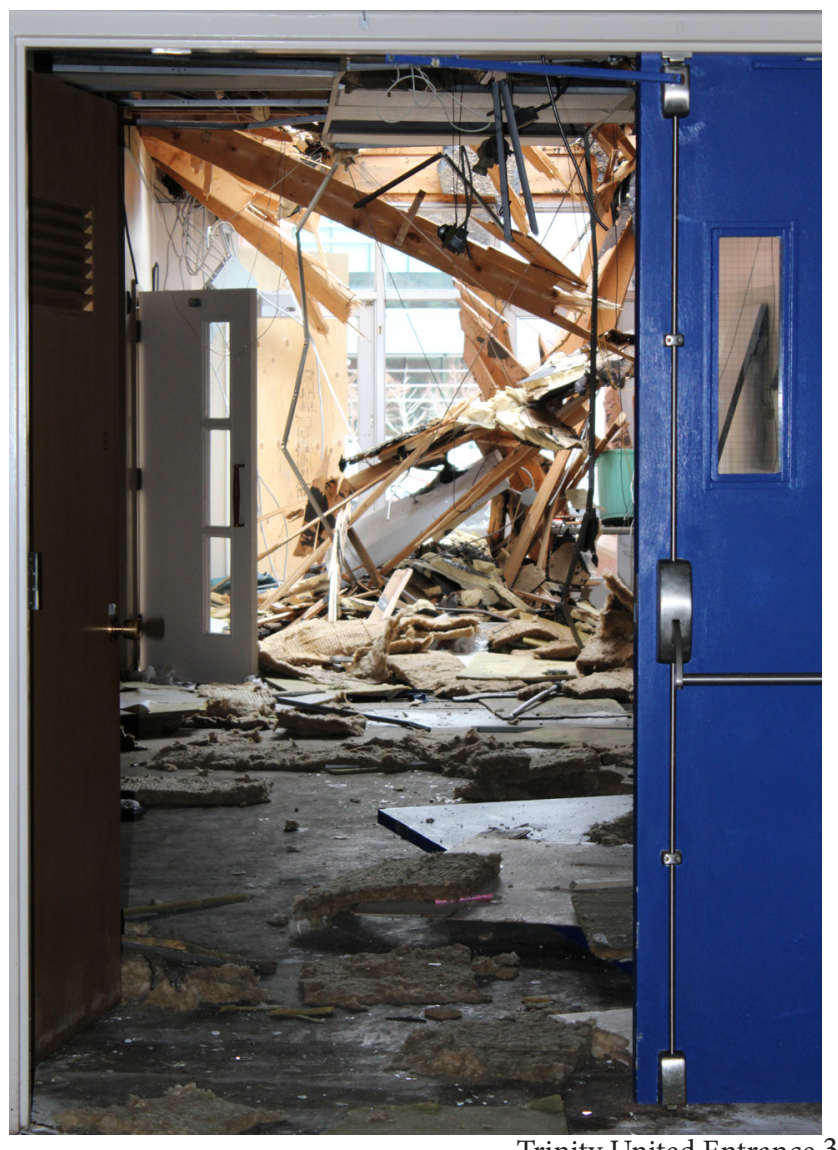


Abstract

As the religious landscape and demographics of South-Western Ontario begin to change many congregations can no longer maintain the religious buildings that house them. More and more churches are on the verge of being vacated or are in fact sitting empty with no clear plan for its future. This continuing trend is leaving holes in the urban fabric of towns and cities, which begs the question: should some buildings simply be allowed to die?

This thesis will research possible adaptive re-use strategies of empty churches in South-Western Ontario, particularly in the City of Kitchener. This architectural condition will be researched through a community lens where the qualities of human engagement within the space are privileged and along with the building's state of abandonment are the foundations of any intervention and transformation. From a brief catalogue of buildings in need of repair three will be studied and one will be imagined with a future intervention that may enrich the community in ways as yet unimagined by the town stakeholders and administrators.

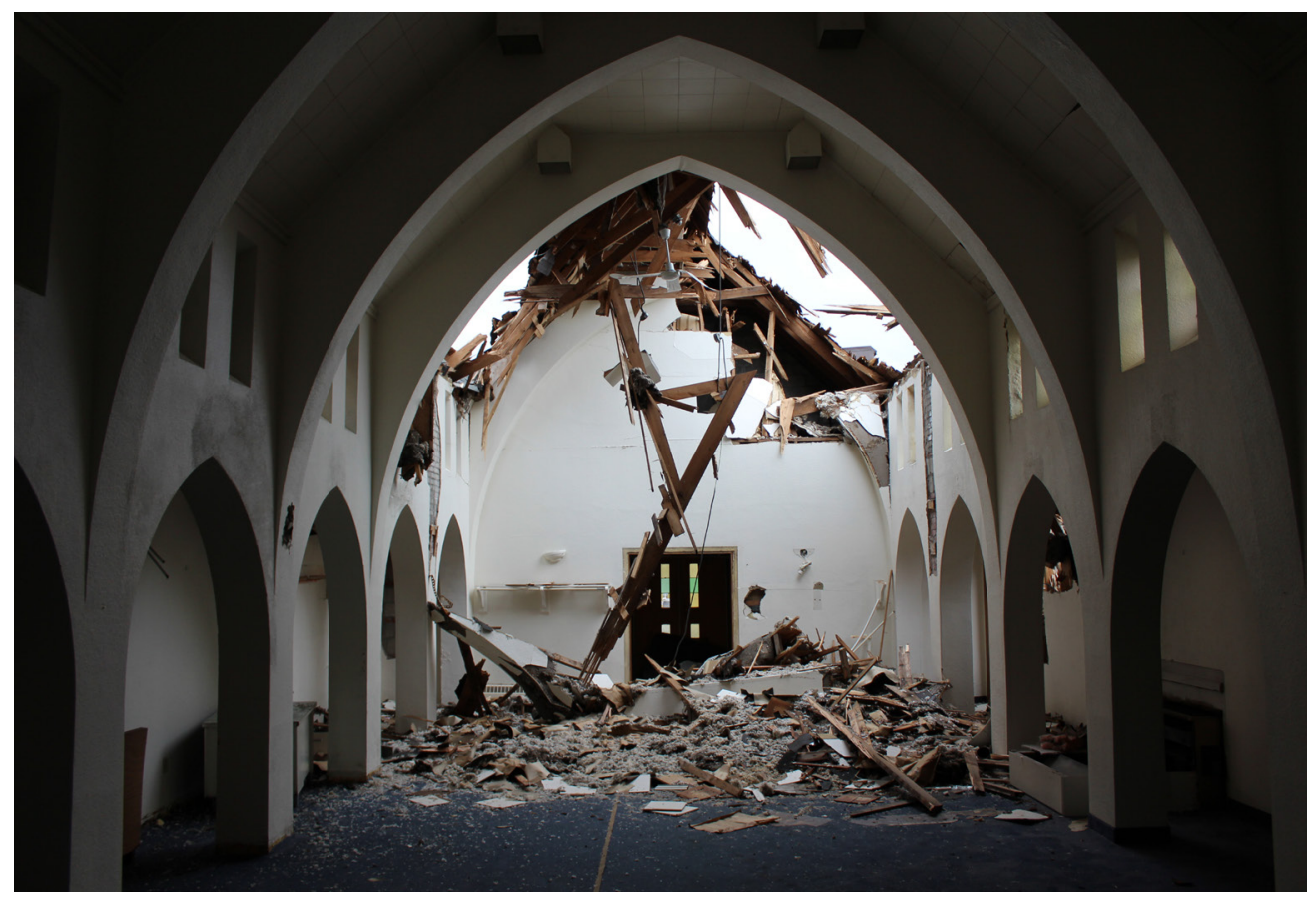




\section{Table of Contents}

Aknowledgements

Abstract

Table of Contents

List of Images

Introduction

Document 1: The Sites

Document 2: Character Defining Elements

Synthesis

Imagined Interventions

Post Script

Appendix A

Early narrative map. 


\section{List of Images}

Image 1. Trinity United Entrance

Image 2. Trinity United Chapel

Image 3. Early Narrative Map

Image 4.Zion United side entrance

Image 5. Zion United front lawn

Image $6 . \%$ of Canadians who identify as...

Image 7. Trends in Disaffiliation, by Demographic Group

Image 8. Trinity United Chapel Exterior

Image 9. Iglesia Skate

Image 10. London Garden Winter

Image 11. London Garden Fall

Image 12.Londong Garden Summer

Image 13. S-Dunstan-in -the--East after the Blitz

Image 14. Kitchener City Center map

Image 15. Synthesis

Image 16. Trinity United Bulletin outside

Image 17. Trinity United Bulletin inside

Image 18. Trinity United Church
Pg. 3 Image 19. Character Defining Element Sketch (mind)

Pg. 23

Pg.4 Image 20. St. Marks Lutheran Church

Pg. 25

Pg. 5 Image 21. Character Defining Element Sketch (heart)

Pg. 26

Pg. 8 Image 22. See You Next Week

Pg. 27

Pg. 9 Image 23. Zion United Second Church Exterior

Pg. 28

Pg. 10 Image 24. Zion United Second Church interior

Pg. 28

Pg. 10 Image 25. Zion United Church

Pg. 29

Pg.11 Image 26. Character Defining Element Sketch (soul)

Pg. 30

Pg. 12 Image 27. The Record: Zion United Church

Pg. 31

Pg. 13 Image 28. Zion United Church Choir date unknown

Pg. 32

Pg. 13 Image 29. Abandoned mind map

Pg. 33

Pg. 13 Image 30. Trinity United kitchen

Pg. 34

Pg. 14 Image 31. Ontario Map

Pg. 35

Pg. 15 Image 32. City Hall

Pg. 35

Pg. 18 Image 33. Center in the Square

Pg. 36

Pg.19 Image 34. K-W Grand River Hospital

Pg. 36

Pg.19 Image 36. Mount Hope Cemetery

Pg. 36

Pg. 20 Image 37. Victoria Park 
Image 38. Kitchener Market

Image 39. Kitchener Court House

Image 40. Trinity United

Image 41. Zion United

Image 42. St. Mark's Lutheran

Image 43. St. Andrew's Presbyterian

Image 44. St. Matthew's Lutheran

Image 45. St. Mary's Church

Image 46. Eastern Synod Evangelical Church of Canada

Image 47. St. John the Evangelist Anglican Church

Image 48. First Church of Christ Scientist

Image 49. Ukranian Catholic Church of the Transfiguration

Image 50. The Journey

Image 51. Sacred Heart Church

Image 52. Church of the Good Shepherd

Image 53. International Gospel Center

Image 54. St. Paul's Lutheran Church

Image 55. K-W Korean Presbyterian Church
Pg. 36

Pg. 36

Pg. 38

Pg. 38

Pg. 38

Pg. 38

Pg. 38

Pg. 38

Pg. 38

Pg. 38

Pg. 38

Pg. 38

Pg. 38

Pg. 38

Pg. 38

Pg. 38

Pg. 38

Pg. 38
Image 56. Benton Street Baptist

Pg. 38

Image 57. Figure Ground Plan

Pg. 36

Image 58. Religious Institutions in the Downtown Core

Pg. 37

Image 59. Public Transit in the Downtown Core

$\operatorname{Pg} 38$

Image 60. Land Use of Downtown Kitchener According to Pg. 39 Secondary Plan

Image 61. Proximity Map Trinity United

Pg. 40

Image 62. Proximity Map St. Mark's Lutheran

Pg. 41

Image 63. Proximity Map Zion United

Pg. 42

Image 64. Trinity United Axo

Pg. 43

Image 65. Theater Exploded Vies

Pg. 44

Image 66. Theater Details

Pg. 45

Image 67. St Mark's Sketch

Pg. 46

Image 68. St. Mark's Intervention

Pg. 47

Image 65. Zion United Axo

Pg. 48

Image 66. Zion United Section

Pg. 49

Image 67. Zion United Sanctuary

Pg. 50 


\section{Introduction}

What is an Abandoned Building?

The very broad term abandoned in relation our environments can encompass anything from a recently vacated building to a long forgotten dilapidated structure. A unifying factor within architecture is the lack of prescribed program and general public inaccessibility. They are in a type of limbo where decay can freely act upon them.

Taking this broad definition into account an abandoned building then is a building where the owner, main user, inhabitant, dweller, primary care taker has deliberately decided to move on and has not secured its future use. In other words, it is a temporary state, an extreme condition in the fluctuating life cycle of a building, where it no longer is able to fulfill the needs of its previous use. So the structure lies empty and waits for someone or some organization to take an interest in it.

Under this definition most buildings have gone through periods of abandonment of varying durations. Some buildings transition from abandoned to new use quickly and easily, smoothly maneuvering through a changing society. Other buildings do not and begin to languish in their pre-abandoned and abandoned states. Success often requires bold and forward looking strategies with are often difficult for established communities to embrace. It is within such period of abandonment that this thesis and project will situate itself; that window where the site is static, immobile, awaiting a direction forward.

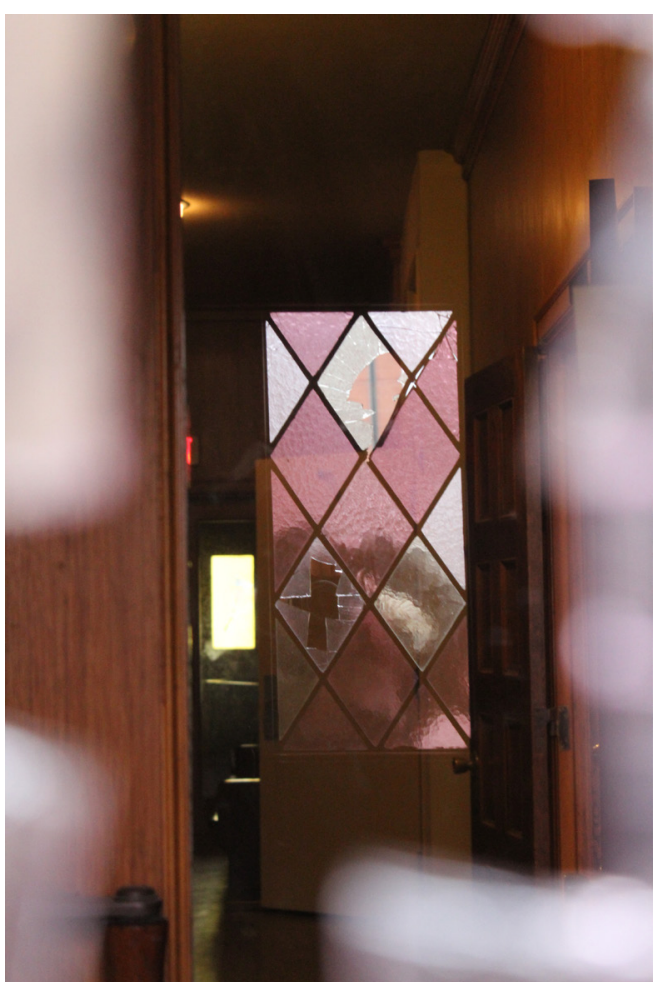




\section{Introduction}

Community churches tend to fall in the latter category experiencing longer periods of abandonment. Increasingly mainstream protestant churches in Canada are on the real estate market as congregations shrink and resources to upkeep their aging buildings consistently dwindle. It appears these buildings have ultimately been left behind by their owners and users whether by conscious and deliberate acts or not. For whatever reason these buildings no longer suit the needs of the original inhabitants who do not have the resources to change the building. Also we must stress here that the state of abandonment is not necessarily the final stage for a building but a transition period, where it has the potential to go in a new direction.

How can architects take advantage of this suspended time period and explore ways of transforming churches in their vulnerable state. Interestingly, in South-Western Ontario and specifically in the City of Kitchener multiple churches find themselves in this state at the same time. Here there is a sense that changes are happening and thus a variety of response might begin to address the multiple cases by devising a re-use strategy as well as creating a network of complementary connections between them.

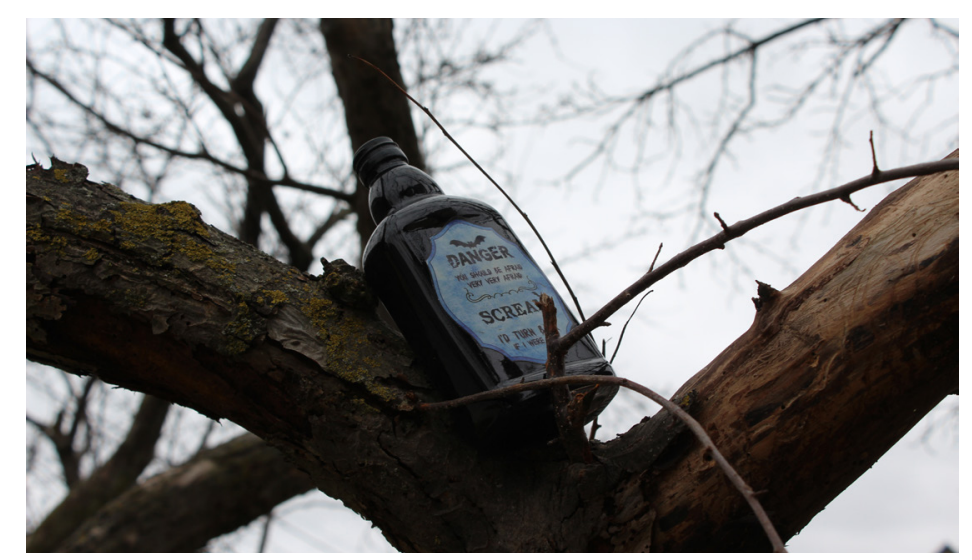


Why are Churches Disappearing?

One of the reasons so many church buildings and properties are on the real estate market is due to the declining number of consistent congregations. The Pew Research Center (PRC) shows this trend in Religious Affiliation in Canada where $41 \%$ of Canadians identified as Protestant and regularly attended church in 1971 compared to $27 \%$ in 2011. In the same time period the unaffiliated have grown from $4 \%$ of the population to $24 \%$. A greater number can be expected in today's population (in 2018/2019) considering how consistent these trends have been over the last 40 years. Taking a closer look at the unaffiliated population brings to light another reason why churches are being sold.

* of Canodians who identify as ...

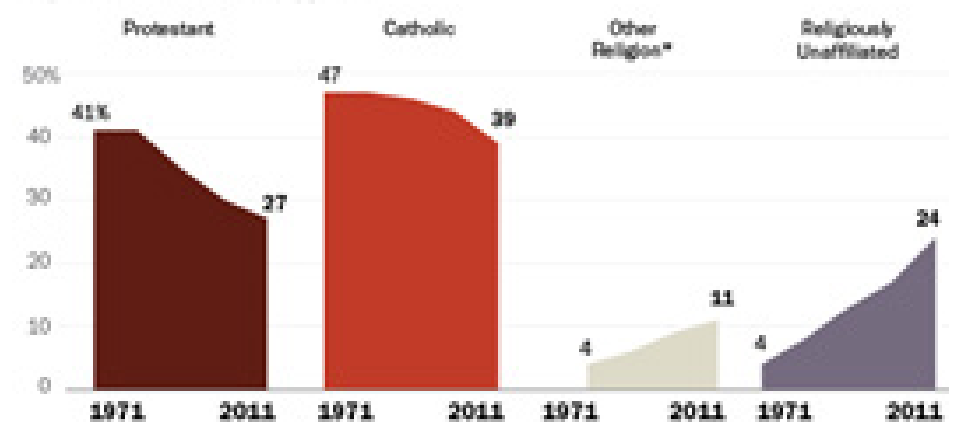

Trends in Disaffiliation, by Demographic Group

S6 who describe themselves as religiously unaffiliated among ...

19711981199120012011

\section{Canadian general public}

$\begin{array}{ccccc}\% & \% & \% & \% & \% \\ 4 & 8 & 13 & 17 & 24\end{array}$

Men

Women

Married*

Unmorried*

\section{Colleze groduate*}

Some college or less*

Native-born

Foreign-born

Younger adults (Ades 25 to 44)

$5-15-20-29$

$\begin{array}{lllllll}\text { Middile aged odults (Ages 45 to 64) } & 4 & 5 & 9 & 14 & 20\end{array}$

$\begin{array}{lllllll}\text { Senior adults (Ades } 65 \text { or older) } & 2 & 3 & 6 & 9 & 12\end{array}$

Sources: 1971-2001 Canada census, 2011 National Household Survey

r2011 Canads General Social Survey

PEW RESEARCH CENTER

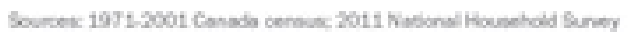




\section{Introduction}

PRC subdivided the members of the unaffiliated by age groups and gender. According to their surveys the only demographic that did not see a dramatic increase in disaffiliation were seniors, aged 65 and older. If younger generations are not attending church then there are fewer new incoming members to compose a steady flow of congregants, thereby reducing many churches to a senior only congregation. Expensive repairs to the buildings are unaffordable, community outreach is not as engaging to younger people and many congregations' visions struggle to be compatible with the changes in contemporary society.

In sum, more and more of Canada's population is not identifying as religious. Within that group it is mostly the younger generations who are increasingly unaffiliated. Based on the data this particular phenomenon of empty religious buildings, for the time being, is constrained to Christian churches.

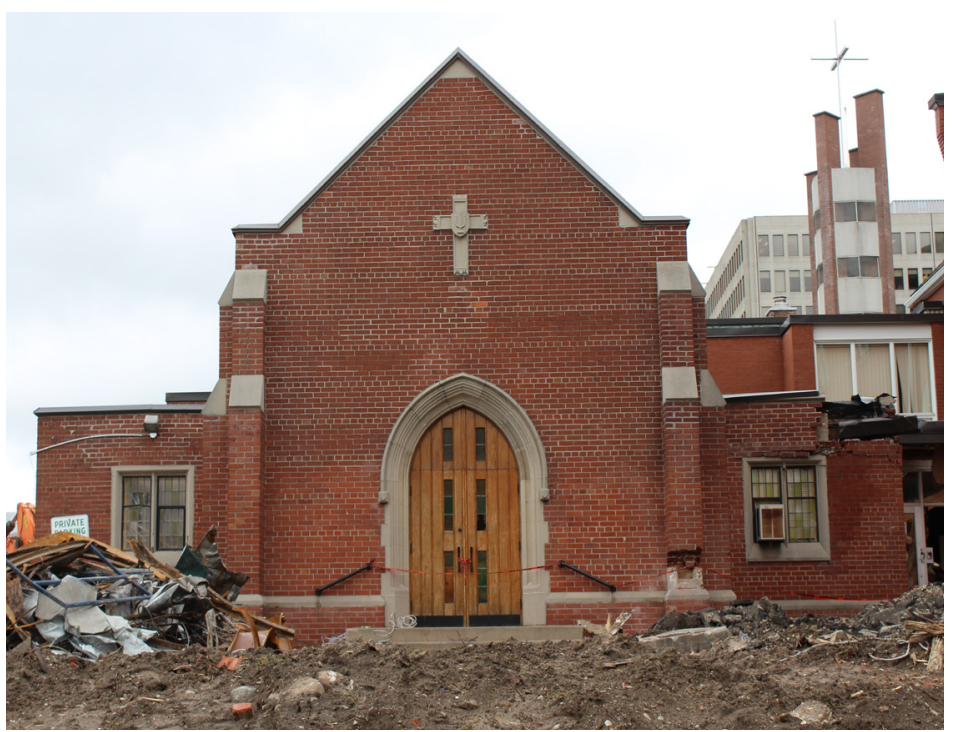


What can Churches Become?

A church for sale or looking for redevelopment is nothing new. Hundreds of churches all over the world have been transformed into a myriad of different uses. Churches have been converted into pubs and restaurants, concert halls, museums, libraries, homes, condos, stores, swimming pools and more. Some use the building's unique architecture as a draw to their new use, others the often central location within their communities and still others enjoy the tension between the lingering sense of a house of worship and their new wholly secular use. For example, Iglesia Skate in Spain uses bright murals and ramps to transform the church into a skateboarding haven while the structure and space distribution remains more or less intact preserving the atmosphere of a church- creating a tension between past and present functions.

An example of note which has been an inspiration and incited many discussions is the London Garden in England. Formerly St Dunstanin-the-East Anglican Church, this small garden was opened in 1970 after nearly 30 years of abandonment. The church was heavily damaged during the Blitz and upon the end of World War II the city decided to leave it in ruins. In the 60's there was interest to use the site once again and a garden was draped over the broken walls of the church. It is quite unique that the City of London did not decide to demolish what was left of the structure and build something new but instead decided to embrace the dilapidated and forgotten state of the church to enrich its new use as a public garden.

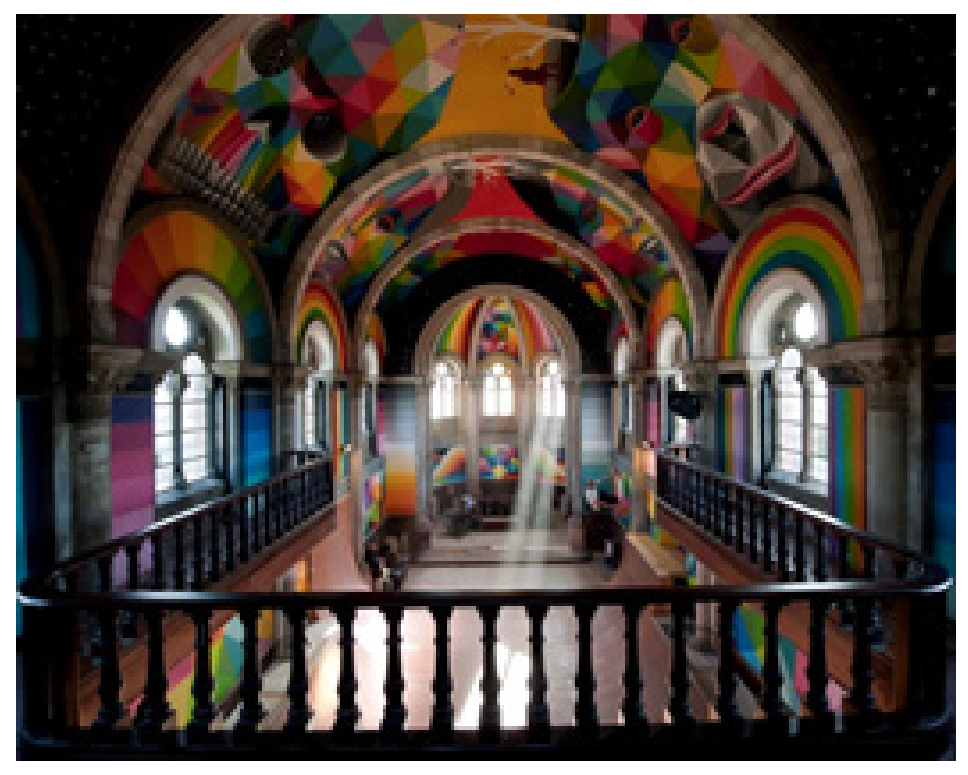



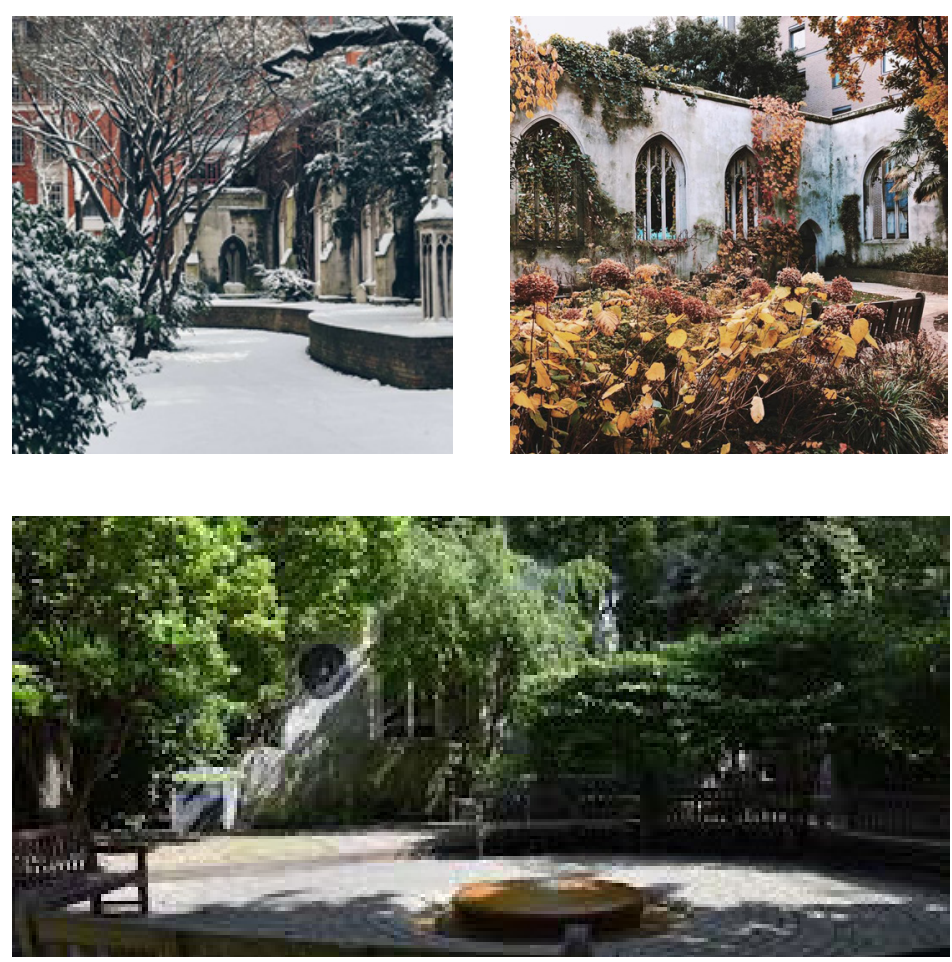

Let us unpack the central aspects of this case; the conscious decision to use the ruins, the cultural significance of gardens in England and the qualities of the resulting space. The choice to maintain the ruins of St Dunstan-in-the-East in the new design speaks of the value of the existence of the structure and of its previous use. It was not necessary to rebuild the church to its pre-war level of functionality and practicality to reintroduce the space to the public. There was a shift of perspective and value was found and assigned to the ruins without any alterations. This shift allowed the open air garden to become a possibility and ultimately a reality.

The new program, a garden, carries a strong cultural connection with both city and country. For centuries the English Garden has been a culturally defining environment. Here ideas of the picturesque and romantic ideals are used within the urban landscape justifying the use of the ruins. The London Garden seamlessly fits into the English culture a place of relaxation and ease within the city's fabric. One might say it has a sense of belonging. It makes sense to have a garden there! 


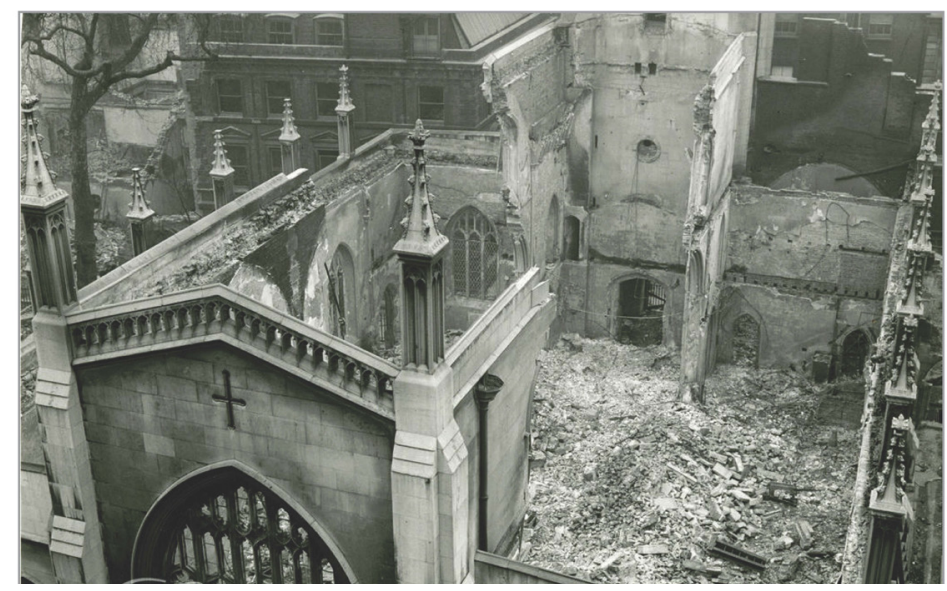

Lastly, the resulting space is a quiet oasis for personal reflection and contemplation. Only a few steps away from a busy London street the garden is peaceful and quiet. It offers refuge from the nonstop movement of the city. The beauty of the garden and ruins exudes serenity and provides a space for spiritual nourishment. The London Garden allows anyone who is in need of a moment to be able to unwind or let their mind wander or meditate. When the London Garden was a church these types of experiences can be said to have been part of what defined it as a church. The depth and subtlety of the new program works in conjunction with the remnants of the previous program. Today, although deconsecrated and transformed into a garden, London Garden still promotes very similar emotions and experiences to its religious predecessor but within a secular setting. 
Document 1

The Sites

Trinity United Church

St. Marks Lutheran

Zion United
Document 2

Character Defining Elements 


\section{Document 1}

\section{The Sites}

During an initial investigation of the Kitchener Waterloo Area seven churches that were empty or on the market were identified. Three of them were in the heart of Kitchener's downtown area. This document focuses on the churches and includes a short history of each as well as insight in to the culture of the congregations.

This document can be read on its own or in conjunction with its sister document which focuses on the character defining elements taken in consideration for that follow. The documents are presented in parallel in order to highlight the connections between their content.

\section{1 - Trinity United 2 - St Mark's United 3 - Zion United}

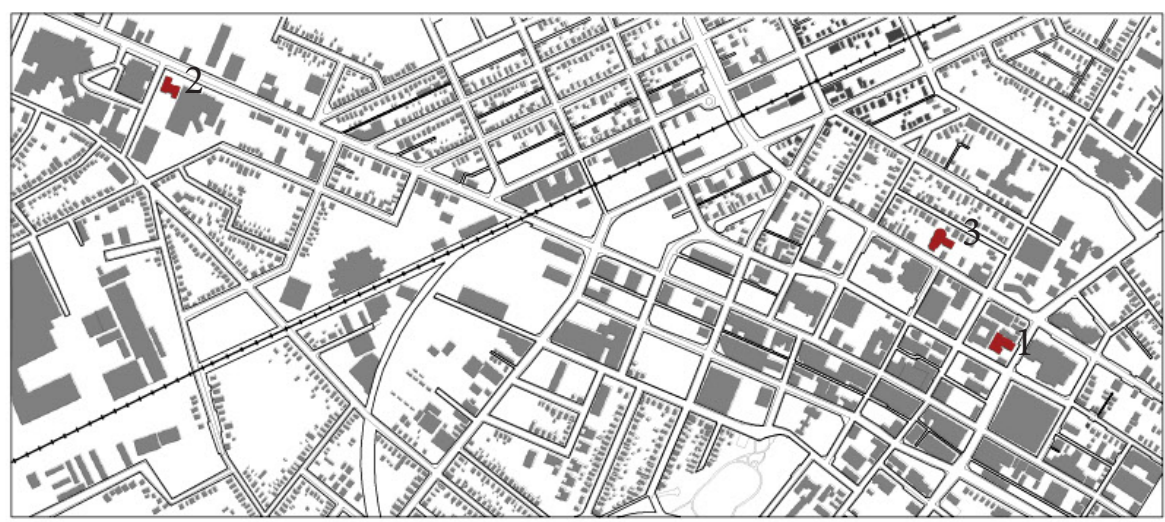

\section{Kitchener City Center}

\section{Document 2}

\section{Character Defining Elements}

These are criteria that were developed from the insights in to the three congregations. They mostly come from recollections that were taken from members either during special events or to mark special anniversaries. Many documents were generously given by members of the congregation. I am very grateful that they trusted me with their treasured memories and keepsakes.

The character defining elements will be introduced through the question of how to evaluate a buildings intangible elements. Each element will be defined and described in terms of how they apply to the sites and the scope of this project.

This chapter is can be read on its own or in conjunction with its sister chapter which focuses on the character defining elements taken in consideration for the interventions to follow. The chapters are presented in parallel to highlight the connections between their content. 


\section{Region of Kitchener-Waterloo}

The City of Kitchener was established $105 \mathrm{~km}$ away from Toronto in the 1850's a village settled by a largely German community. In 1912 it became the city of Berlin and four years later the name was changed to Kitchener in an effort to demonstrate loyalty to Canada and its Allies during World War 1. Since then Kitchener and its twin city Waterloo have grown and become vibrant centers. While the original manufacturing industry has left Kitchener, the service and tech industry have grown along with a changing demographic

Of the many churches in the region of Kitchener-Waterloo that have been sold or are looking for redevelopment options this thesis will focus on three in the downtown historic core of Kitchener. They are Trinity United (74 Frederick Street), Zion United (32 Weber Street West) and St. Mark's Lutheran (825 King Street West). They are all within a 15 minute walk from each other.

\section{How to evaluate?}

How can I analyse and define what the effects of regular attendance to church is for its congregants? How can I outline the base function of a church without getting into the actual message of the religion that was practiced in the spaces? When you asses any building whether an intervention is the end goal or not you take stock of the physical condition of the materials and you compile a list of character defining elements (CDE) into a statement of value. For the most part the character defining elements in an assessment pertain to physical and material features of the building. Intangible elements increasingly have been included as character defining elements in the recent acknowledgement of the cultural and societal importance of the activities that both architecture and landscapes can host. For the purpose of this exploration of Kitchener's Civic Center priority will be given to the intangible elements that a protestant community church offers to its neighbourhood. All three congregations attempted to have their buildings in full or in parts designated as heritage, none of them succeeded. So while the physical elements of the buildings do not merit preservation in the eyes of the municipality I would argue that the intangible and cultural elements provided by the buildings contribute much to the city core and should be the basis of what is imagined as the future of those churches. 


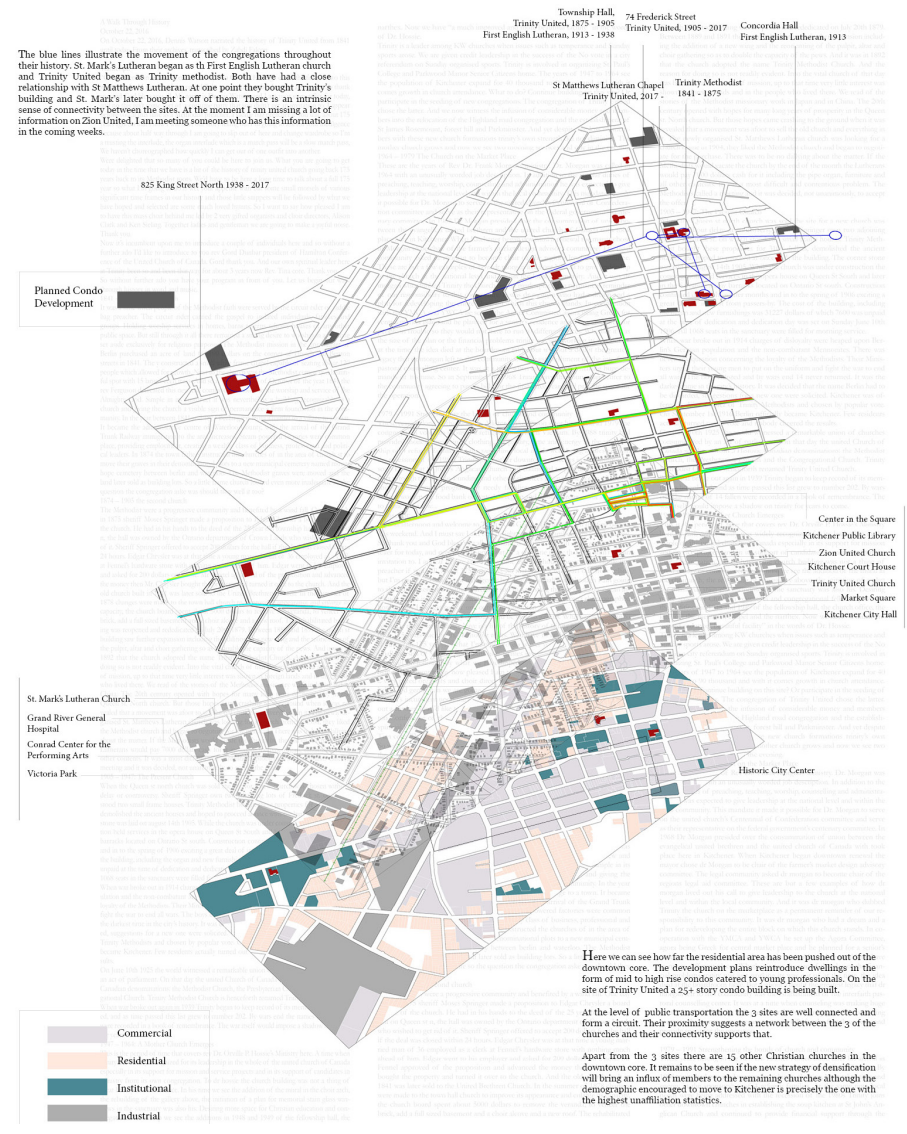

While the analysis of each individual church and congregation is necessary a comprehensive look at all three as a single system is also called for. This in no way is to signify that there are no differences between the three churches, they do however share their most fundamental reason for being and the closure of all three suggests a change of condition in the entire downtown core and in the entire City of Kitchener. The closures have not been distributed as one per neighbourhood, multiple have stood abandoned blocks apart.

Three abandoned churches in one neighbourhood speaks of a trend not of a fluke or extraordinary and surprising circumstances; our society has changed. When all three of the churches were built there was great demand for them in terms of religious people looking for a space to worship but also for a place to build community. People's cravings for fellowship, comfort and family to name a few could all 


\section{Trinity United Church}

The congregation of Trinity United came together in 1841 when a Methodist community of what would become the city of Berlin bought a 100 acre property on the corner of Benton and Church Street. There they built a small white chapel which would serve as their house of worship until 1875 when Edgar Chrysler bought the old town hall on Queen Street. In 1892 the congregation decided to name themselves Trinity Methodist Church (members today are not sure why this name was chosen). In 1905 the St. Matthews Lutheran congregation was looking for a church to hold their services and offered Trinity Methodist 7000 dollars for their town hall church and chattels. Trinity Methodist agreed and the following year had begun building the present day church on Frederick Street on a property they bought from Sherriff Moses Springer. The new building was opened and dedicated on the 10th of June of 1906. Nineteen years later to the day the Methodist Church, the Presbyterian Church and the Congregational Church joined
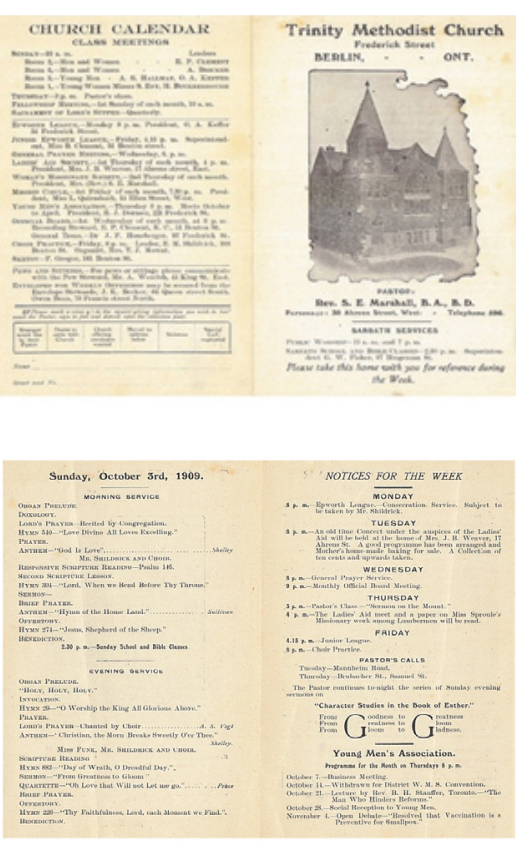

be met through their church community and through the expression of their faith. Today people are not choosing church to meet those needs in the same numbers as they once did however those fundamental needs still exist within the neighbourhood and many people are affected by the many programs, support and aid that churches all provide.

Every church offered unique programs and had defining characteristics that served their congregation and the immediate community around them. With these three churches out of use they are leaving behind social gaps that whether or not they intentionally worked together to fill were part of a support ecosystem in the Civic Centre. These abandoned churches impact the well-being of many people in downtown Kitchener. 


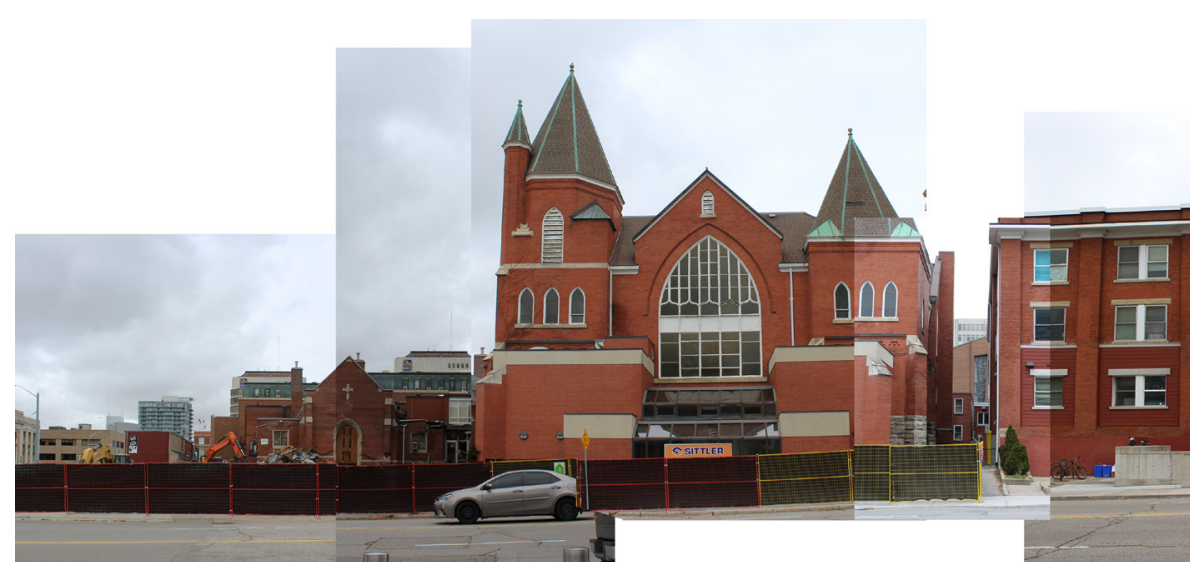

together to become the United Church of Canada and Trinity Methodist Church became Trinity United Church, as it is known to this day. Between 1948 and 1949 the congregation began to grow and the building was in need of expansion. The fellowship hall, full kitchen, chapel, narthex and church offices were added to support and accommodate the growing number of members and functions led by the church.

In November of 2017 the last service was held in the 1906 building and was officially handed over to developers IN8 in April of 2018. Today the congregation meets at St. Matthew's Lutheran Church's chapel on Benton Street.

\section{Character Defining Elements}

These CDEs are based on the similarities and qualities that all three places of worship share. The fundamental function of each is to care for its surrounding community by providing care for three areas or parts of the participant's lives; the heart, the soul and the mind. Weekly services cover those three areas (appendix _ describes a simple itinerary of a service) with a time for worship and music (soul), a time to learn and teach (mind) and a time for fellowship and socializing (heart). That is how the church's ritual translates the intangible elements and serves the congregation. A church's impact goes much farther than that offering many programs and outreach initiatives to help the community in the well-being of their hearts, souls and minds. So in conclusion the character defining elements of these buildings are the way in which heart soul and mind are engaged and nurtured. 
Mind

How does one associate the mind with a place? As an intangible quality I would argue that it comes down to what happens in that place, the activities that fill it. Learning and teaching are a big part of what goes on within church walls on a daily basis. Pastors and leaders teach, congregants listen and learn and there can be much discussion within 'small groups' and bible studies. So in the context of almost every community church the mind can be engaged through learning, and the involvement of discussions and debate. The heart is coming from all the fellowship and community building that happens. Support groups form, people come together to help others in need. All these activities contribute to creating a sense of place, belonging and a sense of home.
The first underlined detail can be interpreted as pride for the congregation's longstanding and firm national loyalty. As they clearly defined "It was the darkest time in the city's history," however they were firm, honest and honourable by sending their community to fight and for not giving cause for suspicion. After the Second World War the congregation saw a time of plenty with growth in members, additions to the church building and seeding of new congregations. 
“1947 - 1964: A Mother Church Emerges

... A time when trinity was widely recognized for its leadership in the whole of the United Church of Canada especially in its support for mission and service projects and in its support of candidates in ministry from its own congregation."

"Trinity is a leader among KW churches when issues such as temperance and Sunday sports arose. We are given credit for leadership in the success of the No vote in a city referendum on organized Sunday sports. ... Or participate in the seeding of new congregations. The congregation of Trinity United chose the latter. And we now witness the infusion of considerable money and members into the relocation of the Highland road congregation and the establishment of St James Rosemount, Forest Hill and Parkminster."

"Dr. Morgan was called in 1964 with an unusually worded job description. ... This mandate it made it possible for Dr. Morgan to serve on the United Church's Centennial of Confederation committee and serve as their representative on the federal government's centenary committee. In 1968 Dr. Morgan presided over the consummation of union between the Evangelical United Brethren and the United Church of Canada with took place here in Kitchener. When Kitchener began downtown renewal the mayor chose Dr. Morgan to be chair of the farmer's market design advisory committee. The legal community asked Dr. Morgan to become chair of the regions legal aid committee."
What is of note within the three congregations of this project is how one repeatedly expanded the engagement of the mind from their congregant base to a larger scale. This would be Trinity United. There are many examples within their relatively recent history where leaders of the church would also be involved in municipal and national councils. This is not to say that the other three churches did not have any impact at all within the municipality though out their entire history. I am simply stating a perceived intentionality of Trinity United to be involved and active in discussion and debate that not only involved themselves but also the City of Kitchener or the United Church of Canada as a whole. Trinity United values the engagement of the mind in making a difference and in challenging ideas and biases through sharing their experiences and point of view. 
This congregation is clearly proud of its accomplishments and influence in shaping Kitchener. They take their success to heart and enjoy their presence within the decision making circles in the city. This congregation also repeatedly sought the opportunity to be in leadership positions through the ministers they employed to lead them. The ministers consistently were part of committees, organizations and initiatives that involved outreach to politically affiliated entities; connections to the mayor's office, vocal participation in municipal decisions (e.g. temperance and Sunday sports), active engagement with the United Church of Canada body to name a few. From their own interpretation of their history there is a sense of importance and a genuine affinity for municipal initiatives.
In short engagement of the mind involves learning and listening put also participation in discussion and activities where the goal is to impart new ideas and to share unique perspectives.

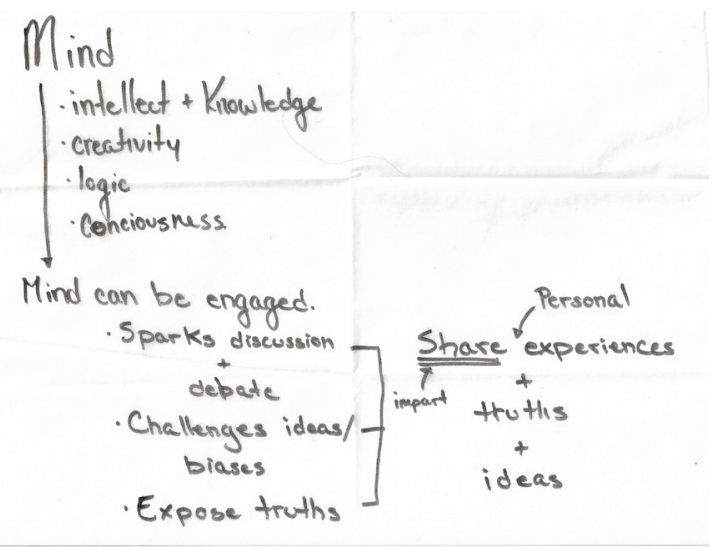




\section{St Mark's Lutheran}

The congregation of St. Mark's Lutheran came together in 1913 as the First English Lutheran Church. There was a growing desire for Lutheran services in English as opposed to German. Many had been gathering in the Concordia Hall where Rev. M.J. Bieber held service in English. They officially organized as The First English Lutheran Church on February 2nd 1913 with 82 members. After two months the congregation made an offer to St. Matthew's Lutheran church for their building on Queen St North across from St Peter's Lutheran Church. This was the very same building that Trinity United had converted from town hall in to a church and occupied from 1879 to 1905. First English Lutheran Church bought the building for 14000 dollars. Once moved in they began renting the building to the Red Cross Society when the congregation was not using it. (The Queen St N building was demolished in 1958 after being owned by the Public Library for 10 years.)

By 1918 the congregation had grown to 400 members and there was talk of finding a new church building. In 1938, with the Great Depression barely behind them and on the eve of the Second World War, a house on the corner of King St and Green St. was bought and demolished to build a new church. While the building was under construction the congregation met in the neighbouring Kitchener Collegiate Institute (KCI). On February 2nd 1939 the congregation moved into the building that housed them until earlier in 2018. Three days after moving in the building was dedicated and the congregation changed their name to St. Marks Lutheran Church. They can now be found as Trillium Lutheran Church where they merged with the St. John's Lutheran Church and the Lutheran Reformation congregation.
Heart

The heart is coming from all the fellowship and community building that happens. Support groups form, people come together to help others in need. All these activities contribute to creating a sense of place, belonging and a sense of home.

Heart is all about fellowship and people. Many times the phrase "heart of a place" comes up in churches. They mean the heart or the intention of the people of that congregation. It is about building community and a sense of place. These community churches want to build a home where people are comfortable and look forward to spending their time there. They want to create an environment that fosters meaningful connections through positive interactions between people. 


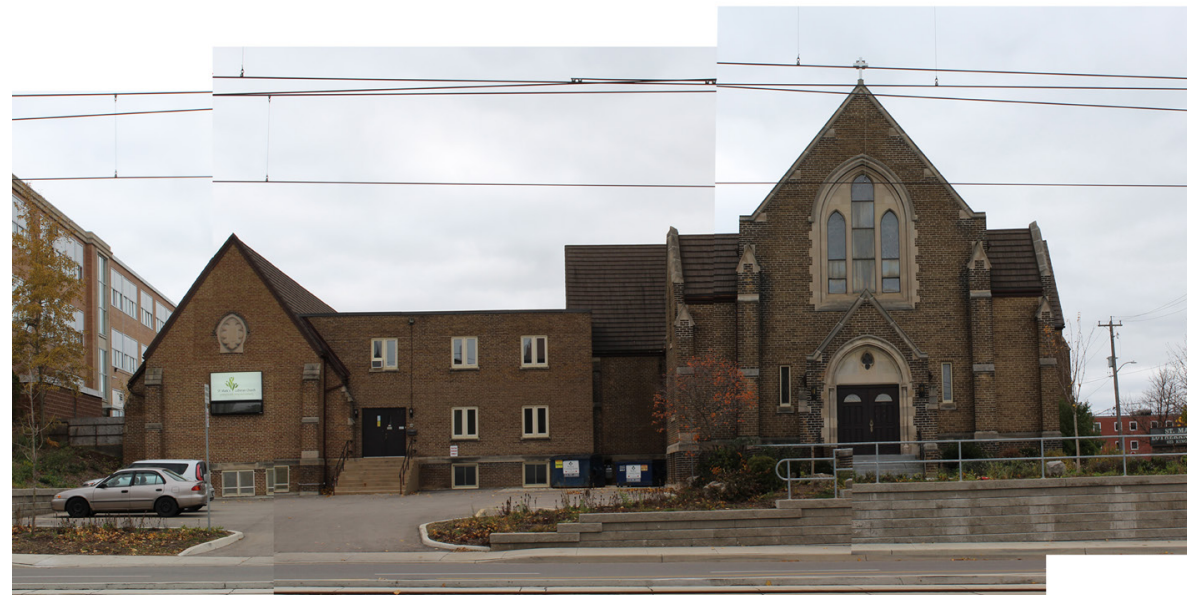

Throughout their time beside KCI and the Grand River Hospital, St Mark's developed many programs to work in tandem with its neighbours creating a community care culture within the congregation. In 1972 St Mark's contributed \$4 500 towards the building of the cardiac unit at the general hospital to offset some of the community's costs. Since 2006 the congregation has provided a breakfast program for the high school students next door. Most notably every Wednesday evening they get together for a community meal. This tradition was born out of potluck dinners on the Wednesdays during Lent.
When a place is described as having heart is means that the people who inhabit it are generous and welcoming. It means that spending time there can nourish your heart. In the case of the three sites some portray their sense of heart more openly than others. It is a quality that is more defined by the people and the culture of the congregation than the building itself. The brick and mortar building on its own may not produce that same effect but the memory of it can be quite powerful. If we were to take one of the sites, Trinity United for example, their sense of heart would be revealed through speaking with members of the congregation and experiencing church life with them. While it is very much there it is not one of their most prominent characteristics. St. Mark's Lutheran on the other hand has placed community ministry and a weekly community meal in the forefront of their ministry. For over 20 years a weekly meal has been served at their parish hall, a tradition that was borne out of the desire to keep gathering out of the sheer enjoyment of being together. 


\section{“Lent 2002:}

In the afternoon of the last Wednesday in Lent 1997, Richard Gingrich was in the Kitchen making coffee for the potluck suppers we used to have during Lent. A couple from Winnipeg, Daryl and Cindy, found their way into St Mark's, and into the kitchen. They were new in town, didn't have money or food, and were looking for help. Richard offered them a cup of coffee, started talking to them, and ended up inviting them to stay for supper.

After supper Daryl and Cindy said,

"See you next week."

Of course, there was not going to be any "next week"- this was the last Wednesday in Lent, potlucks were finished for the year. But the potluck folks thought about that and said,

"Why not? We like eating together like this, let's continue." And they did. Five years later potluck suppers are still going on, every Wednesday...”

- Harold Remus

This excerpt was taken from a book St Mark's published in 2007 with testimonials about the dinners and their impact on the community. The book was aptly named See You Next Week. This anthology contains 60 personal anecdotes of how the fellowship, food and hospitality of this program has shaped the lives of the congregation and the wider community around it. They mention how the dinners brought people to other
A heart can be nourished in many ways, however in the context of the three sites and the intent of this project it is being defined as the product of community in creating a sense of place and home.

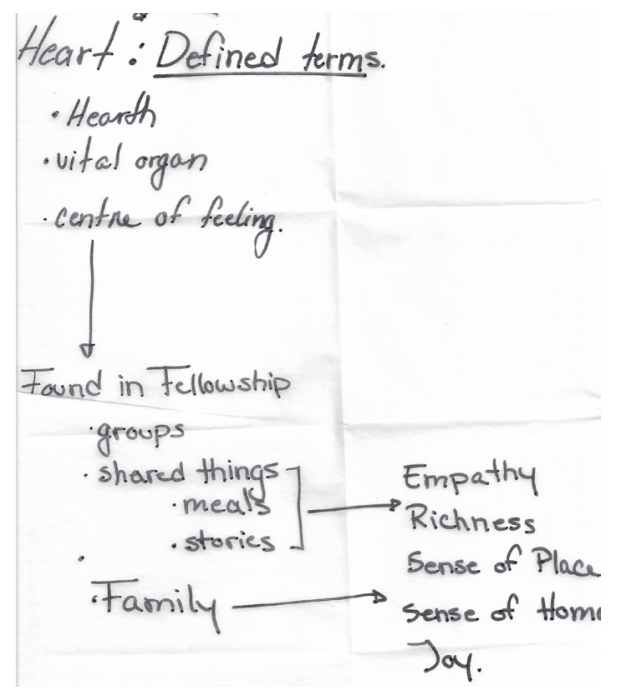


programs that the church offered like a single mothers' group, a six week community kitchen course, AA meetings, distribution of monthly grocery vouchers and The Clothing Rack to name a few. St Marks provided much needed support to Kitchener's downtown core where there are many transient people and low income families. The essence of who the congregation as a whole wanted to be was summarized by Marilyn Shaw, a long-time member and leader of the Community Ministry.

“These community dinners have continued leading up to St. Mark's merging with two other congregations in recent time. When last contacted in December the new congregation was struggling to find an appropriate venue for their weekly dinner and it is very likely that they could cease operations indefinitely"

These community dinners have continued leading up to St. Mark's merging with two other congregations in recent time. When last contacted in December the new congregation was struggling to find an appropriate venue for their weekly dinner and it is very likely that they could cease operations indefinitely

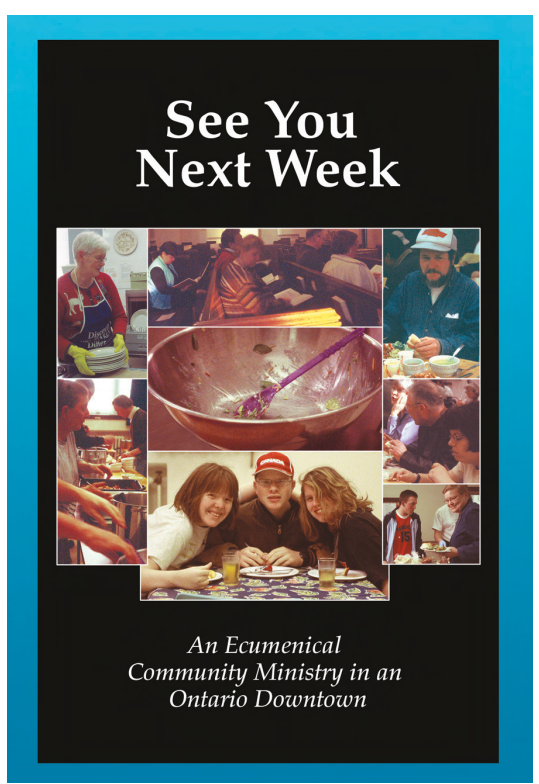




\section{Zion United}

The beginnings of Zion United go back the furthest of the three congregations. In 1839 Evangelical missionaries from Pennsylvania began their ministry in the villages of Berlin, Bridgeport and Waterloo. The following year an Evangelical Sunday School was organized and by 1839 two churches were founded with a total of 26 members; one in Waterloo and the other in Kitchener. This is the beginning of the congregation of Zion Evangelical Church.

For the next three years members gathered in the village schoolhouse, John Hoffman's carpentry shop and at member's homes. In 1841 a small frame chapel was built on Queen Street South. This building was moved in 1866 to what is now Duke Street East and promptly replaced by a brick building on the old site. Up to this point Zion had been part of a circuit where pastors would travel between congregations and divide their time amongst them. In 1867 a Conference session was held in St. Jacobs where it was decided that Zion would no longer be included in the circuit and would have a full time pastor
Soul

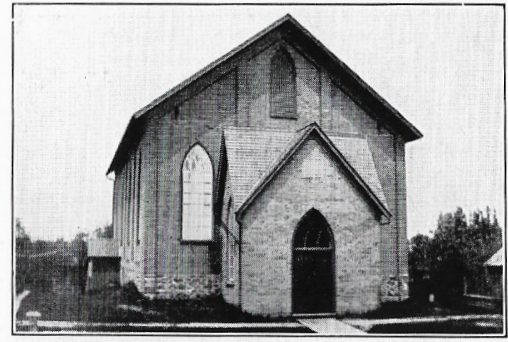

THE SECOND CHURCH, $1866-1894$

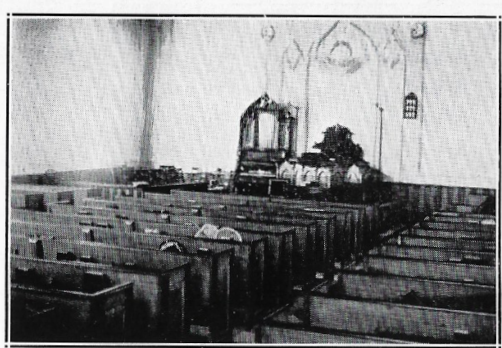

INTERIOR OF SECOND CHURCH
Of the three CDE's soul is the most personal. Your soul is touched when something from an immersive experience resonates with you very deeply. Many church goers would say that worship touches their soul, others would say that a particular message one Sunday really impacted them.

There are many ways to reach a soul, it can be through vulnerability, through beauty, through the awe inspiring and sublime, through healing and comfort, all extremely personal and private experiences. I was in conversation with a pastor in Kitchener and through discussing this project he shared a life changing experience he had. While in Connecticut visiting his son they attended a midweek evening candle lit service in the town's Anglican cathedral. There were no instruments only voices, the entire place lit by candle light. The church was packed, there was standing room only. Despite the uncomfortable conditions for the two hour long service it was a transcending experience for him. His point was that when an experience can be interpreted in 
dedicated solely to its congregation. In 1867 a Conference session was held in St. Jacobs where it was decided that Zion would no longer be included in the circuit and would have a full time pastor dedicated solely to its congregation. After 26 years as a separate church the 254 members decided they were in need of a new, larger church building so in 1893 the corner stone was laid for the building on Weber Street. In 1915 the addition of a Sunday school room, often called the round room was begun behind the main building and was dedicated in 1916. In 1922 Calvary Evangelical church was

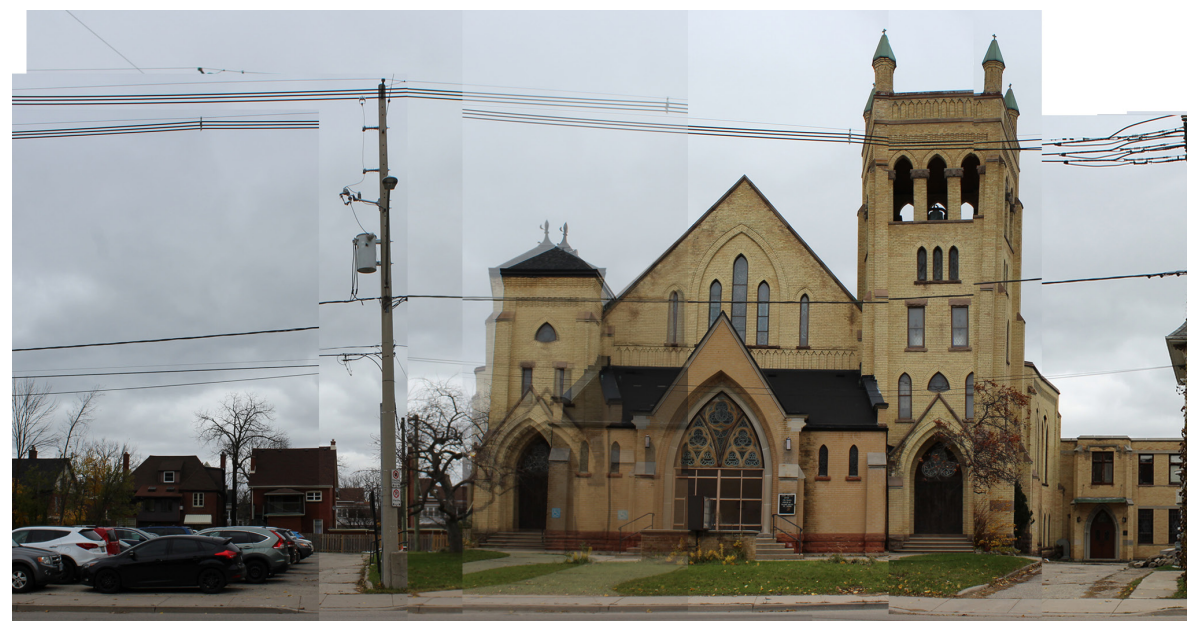

many ways each individual can take away what they needed from it, transforming the experience into something tailored for each individual. These experiences although personal can occur in both group settings or in individual activities.

The theme of music began to emerge in the recollections Zion United's members. They spoke of music as an inspiration, as something that brought them joy, as a time honoured tradition to have a robust choir and an orchestra and as something that they personally came to value. This was the congregation that most obviously presented how the soul was touched in their culture and traditions.

As was previously stated a soul can be touched in many ways. Here we define it as a deeply personal experience that transforms an individual in a very personal way. 
planted and dedicated in September of that year. In 1936 a second seeded church was dedicated as Olivet Evangelical Church.

A fire broke out in the main sanctuary in 1942 and caused extensive damages. Four years later in 1946, the Evangelical Church merged with the United Brethren Church causing a change in denomination and name from Zion Evangelical to Zion United Evangelical Brethren. In 1958 the east wing was built to accommodate offices and administrative spaces. Fire once again destroyed part of the main sanctuary in 1965 only two months after a new organ had been dedicated. In 1967 on Canada's 100th birthday the congregation celebrated their own 125th anniversary and the union of the United Evangelical Brethren with the United Church of Canada modified Zion's name to Zion United. In 2006 Rockway Mennonite began renting the church as a means of additional income. When the congregation of Zion United dissolved in 2016 the building was sold to a private owner and has remained unused ever since.

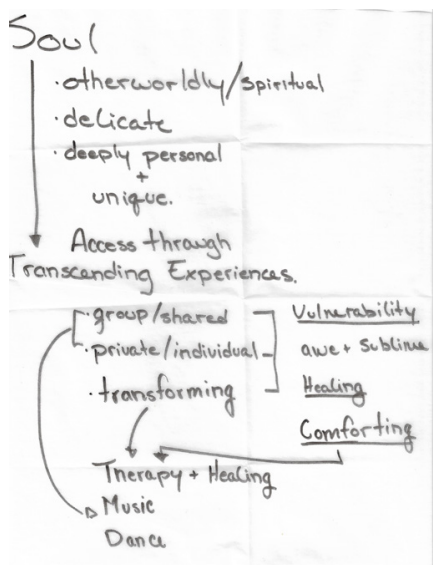


Over the years the congregation of Zion United gathered members' recollections and invested in very detailed histories of both the congregation and the history of the evangelical church in Ontario. The Evangelical denomination which seeded this congregation was a very disciplined and principled one whose teachings and beliefs were in stark contrast with the daily living of many residents of Kitchener in the mid 1800 's.

"But the uncompromising attitude of the Evangelical church on some moot issues no doubt kept many out of the Evangelical ranks. For example the denomination's early declarations against the manufacture, sale and use of intoxicating liquors seemed fanatic to some dwellers in this domain."

In one instance a pastor was hung in effigy on King Street for his sermons denouncing drunkenness. As time went on the denomination softened some of its rigidity and its amalgamation with the United Brethren and eventually the United Church changed some of the stricter rules. Members' recollections from the 1980 echo the disciplined nature of the denomination with accounts of labeled and assigned pews, rigorous attendance to weekly sermons and the Sunday school that followed. Along with the disciplined nature of the denomination a defining characteristic has been the music performed at Zion United.

"Since its inception the choir has always played a vital part in the worship of our Church. The first church, 1841-1865, had a choir under the direction of John Thomas, a man of many talents and a tireless worker"

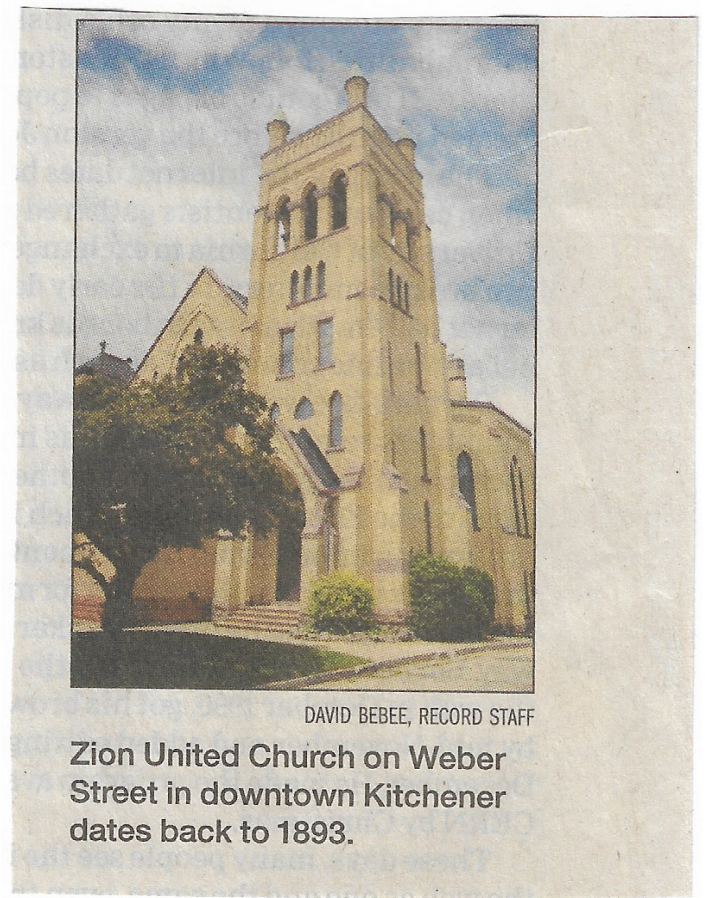




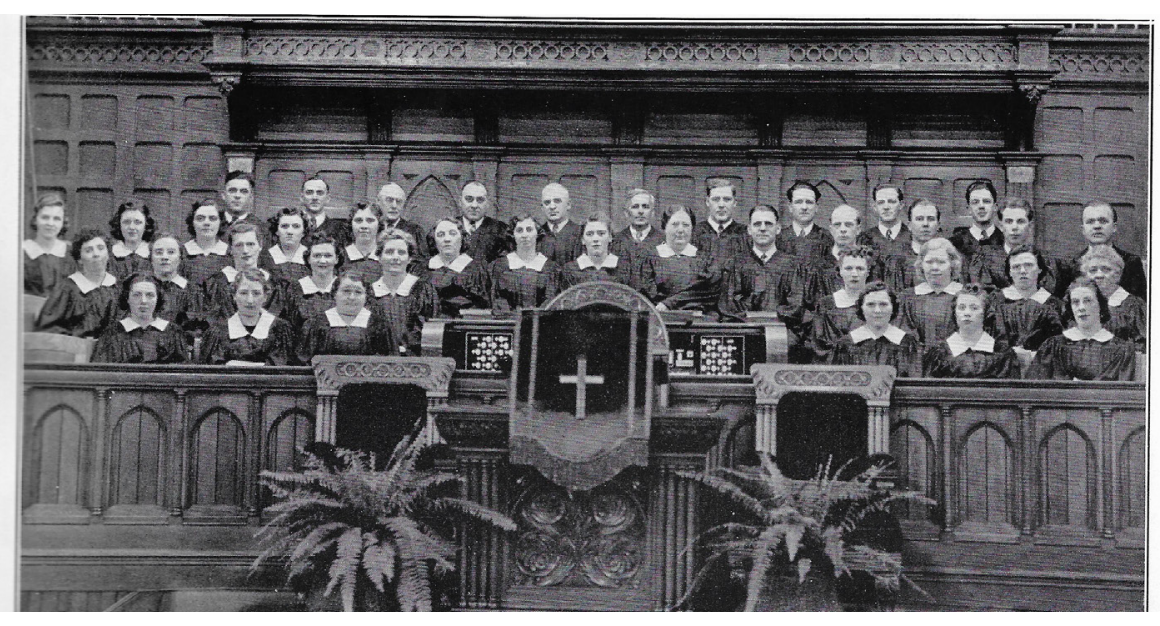

Many personal anecdotes mention participation of the choir or the $15-20$ piece orchestra that regularly performed in services and at special occasions. .

"For as long as I have been a member of Zion, music has always been an important part of the life of the congregation. Music in worship, in Sunday School, in special performances of cantatas always seemed to be something with the Zion congregation expected to be of a $g$ high level. In thinking about my memories of Zion, There is no question that among my fondest recollections is the realization of just how much this 'music of Zion' has affected my life."

- Ken Christner 


\section{Synthesis}

We have defined abandoned buildings in the context of this project, discussed the causes of church abandonment in Ontario and Canada and explored the values of an abandoned church through the example of St. Dunstan-in-the-East, now called the London Garden. Documents 1 and 2 focused on the downtown Core of Kitchener identifying three cases of abandoned churches and explained how the value of each building is evaluated through character defining elements. Each church was described and analyzed alongside the Character Defining Elements that would be privileged in the speculation and design of its intervention

We have learned that a building need not be in pristine condition for there to be a meaningful and successful intervention on the site as seen in St. Dunstan-in-the-East. Of the three sites Trinity United was in the worst state of neglect and was slated for demolition. This is an exciting moment to inject an intervention when there is so much flexibility in the material and physical aspects of the church. The intervention then became a question of how to imagine an installation or temporary use that took advantage of its expendable state while still retaining its essence through the conceptual character defining element of intellectual pursuits.

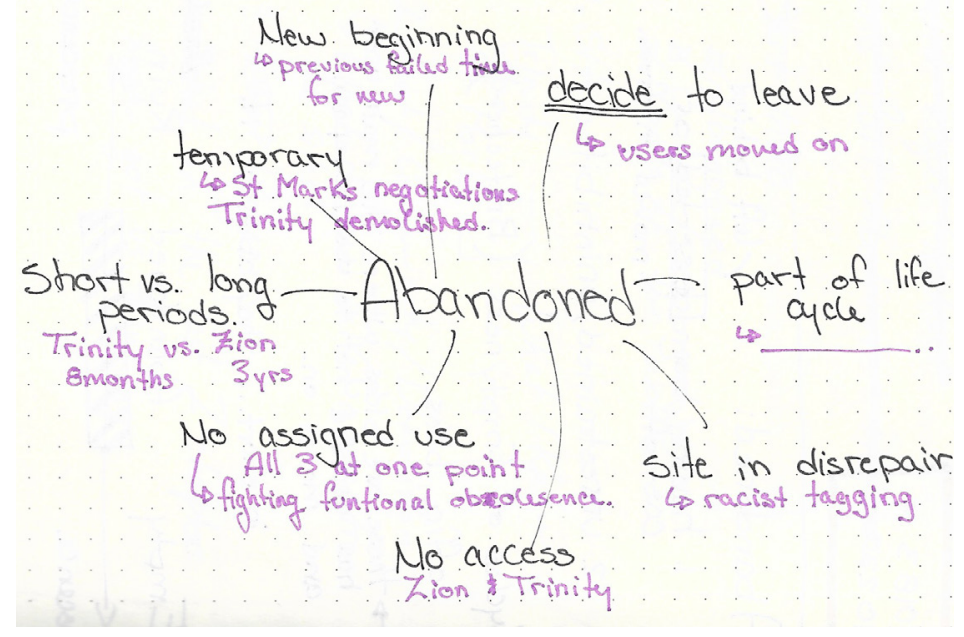


Synthesis

Taking this line of thinking further, would an intervention benefit from the removal of parts of a building if the intangible elements were the only thing privileged? That is the experiment in the imagined futture of St. Marks Lutheran where the heart and sense of place and home is the primary focus. Taking away areas that do not support or contribute to the character defining element could emphasize areas which have a greater effect and importance.

In order to understand and illustrate how the three churches construct a network an analysis of Downtown Kitchener was done. Public transportation, land usage and the city's secondary plan were taken in consideration. A proximity map detailing the area 600 meters around each Church shows the city of Kitchener at a smaller scale.

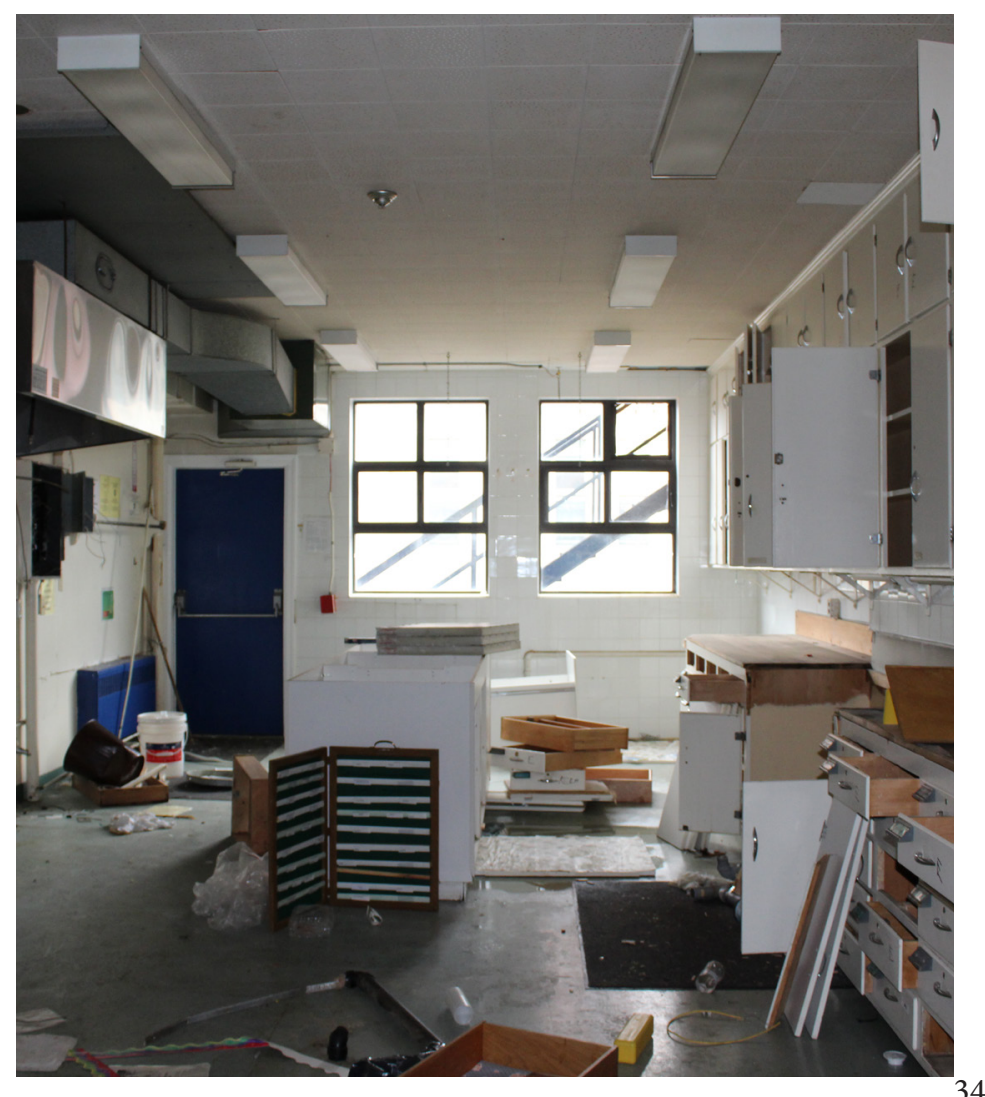




\section{Synthesis}

\section{Kitchener, ON}

Founded: 1912 as the City of Berlin

Population: 242, 368

Area: $136.9 \mathrm{~km}^{2}$
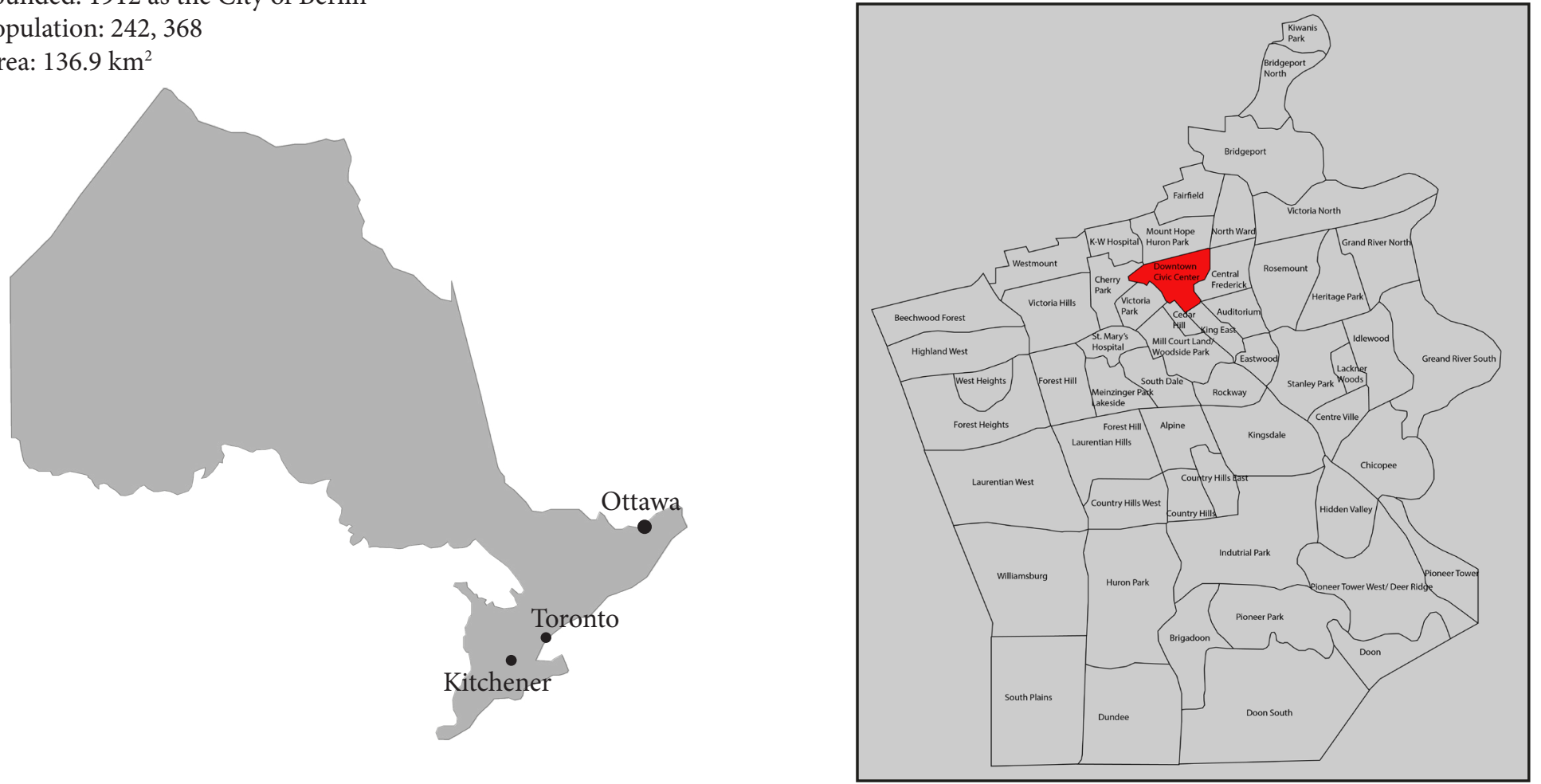

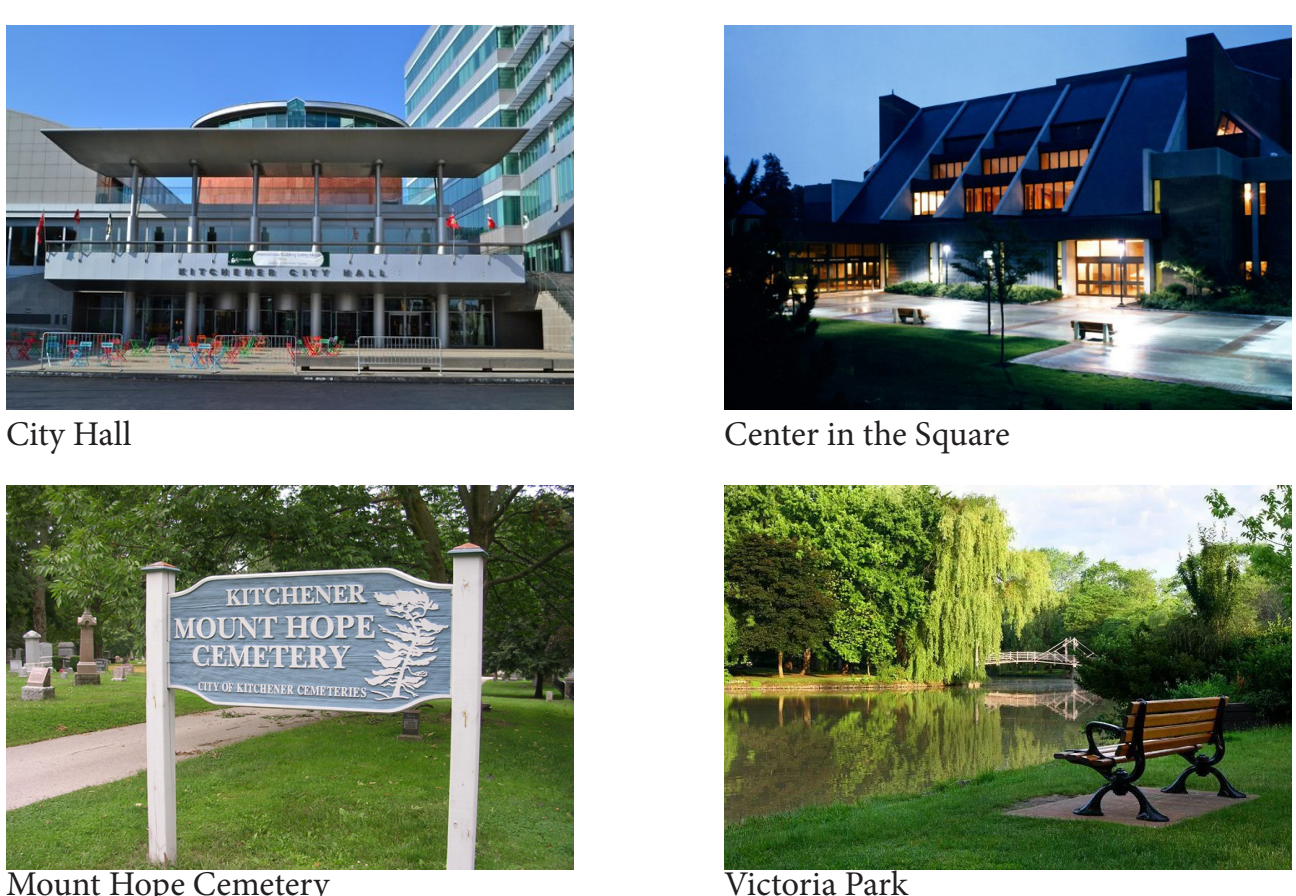

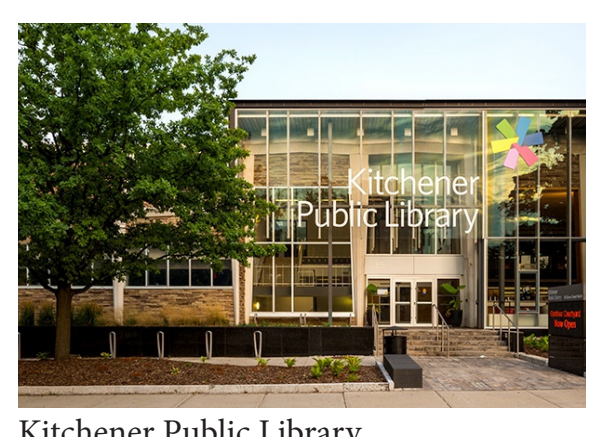

Kitchener Public Library

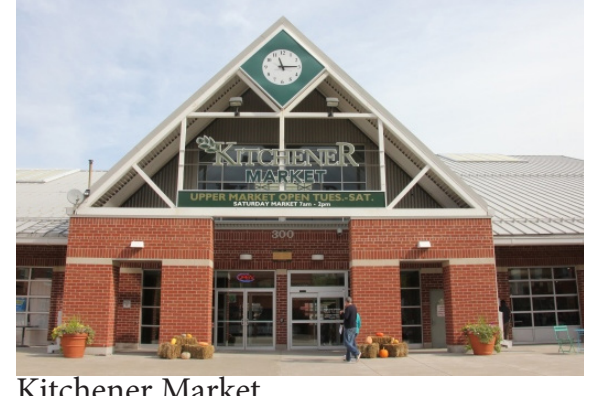

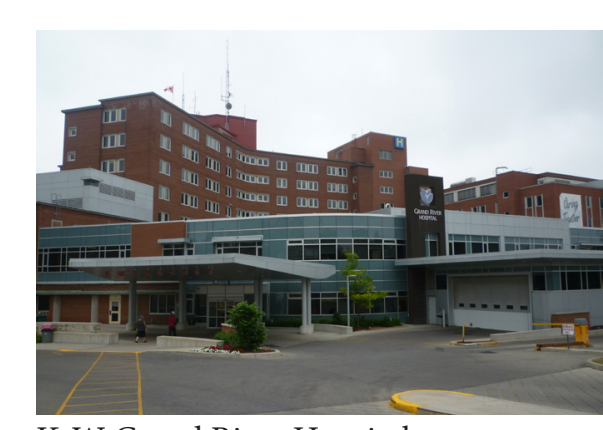

K-W Grand River Hospital

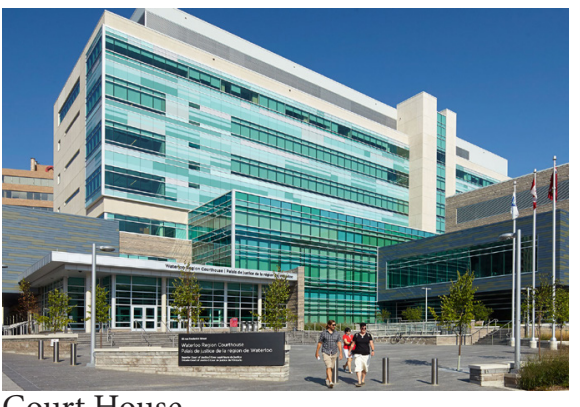

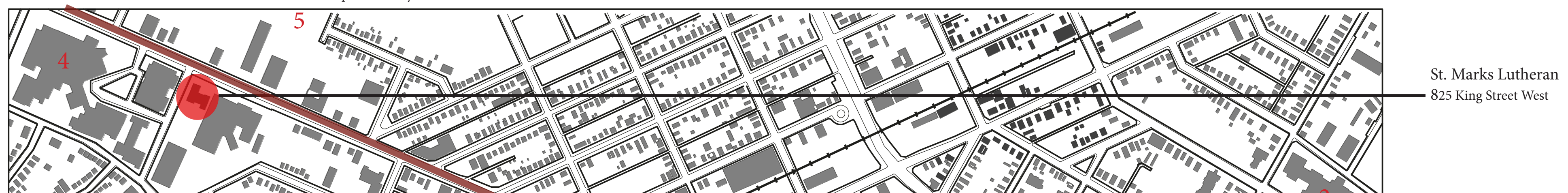
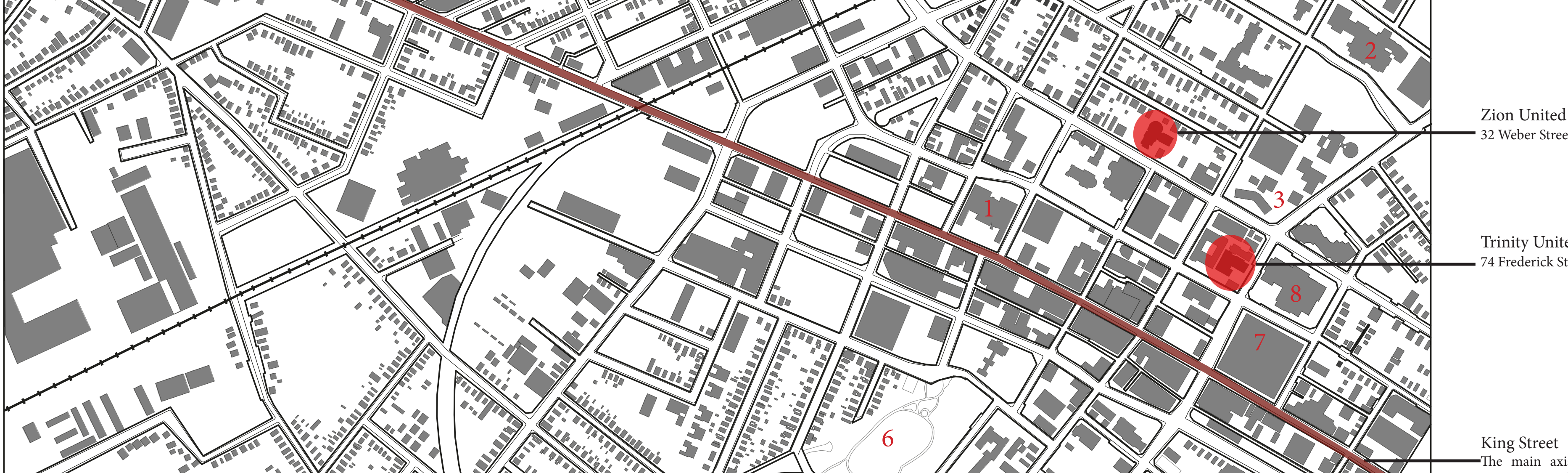

$1+$

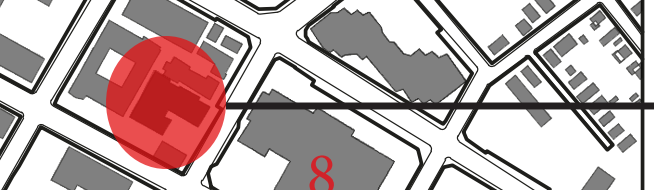

Trinity United

74 Frederick Street

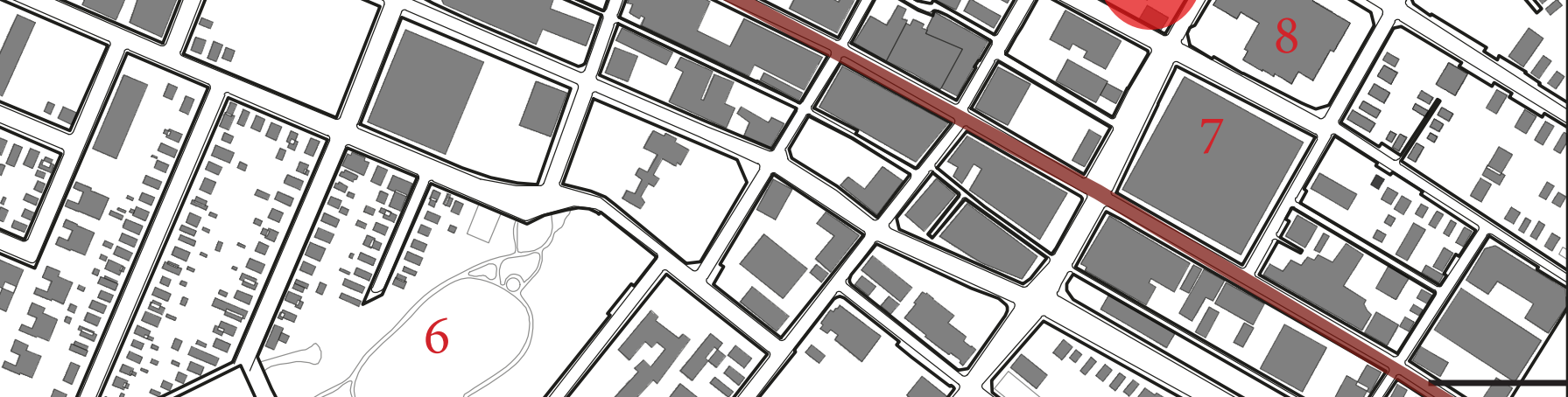

of Downtown Kitchener 


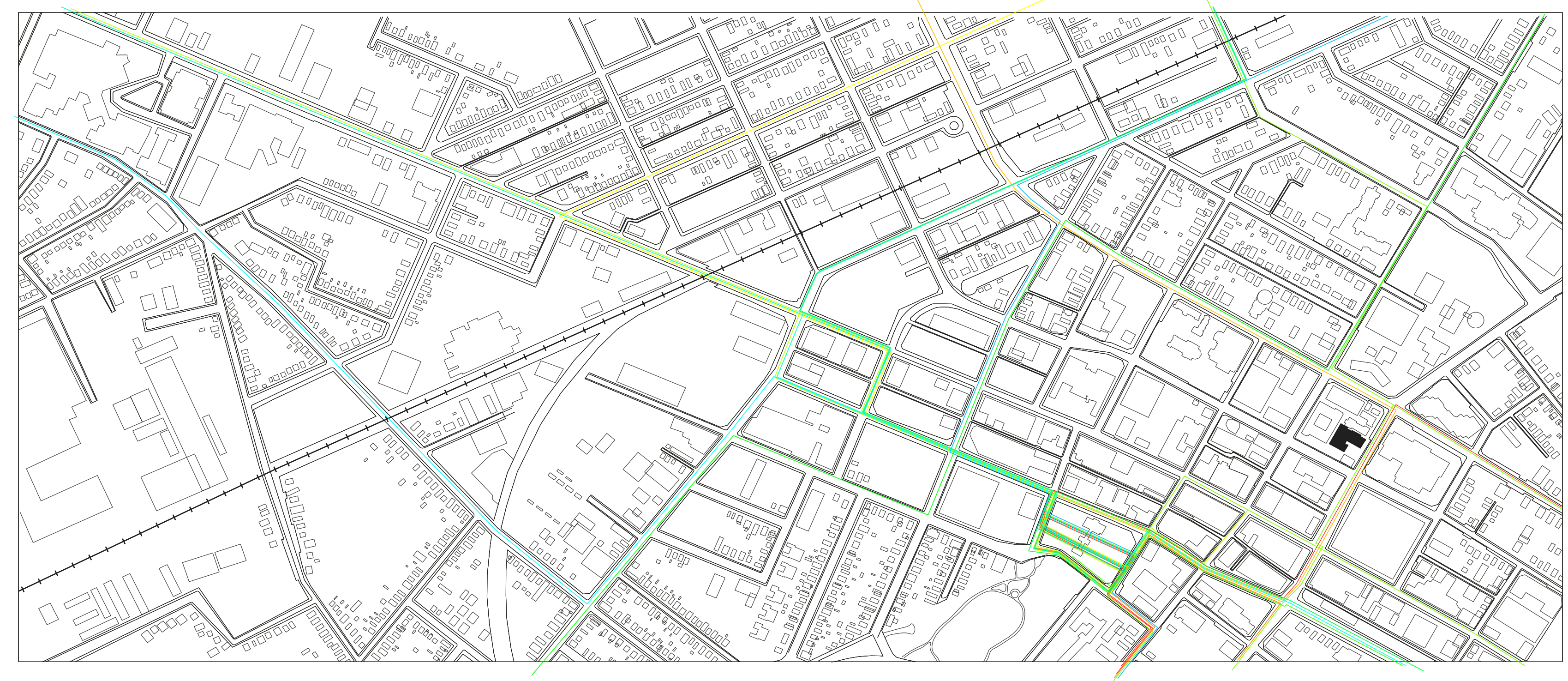

Route 1:

Route 2:

Route 3:

Route 4:

Route 6:

Route 7:

Route 8:

Route 11:

Route 20:

Route 22:

Route 34:

Route 91:

Route 200:

Route 204:

Public Transportation in the Downtown Core 

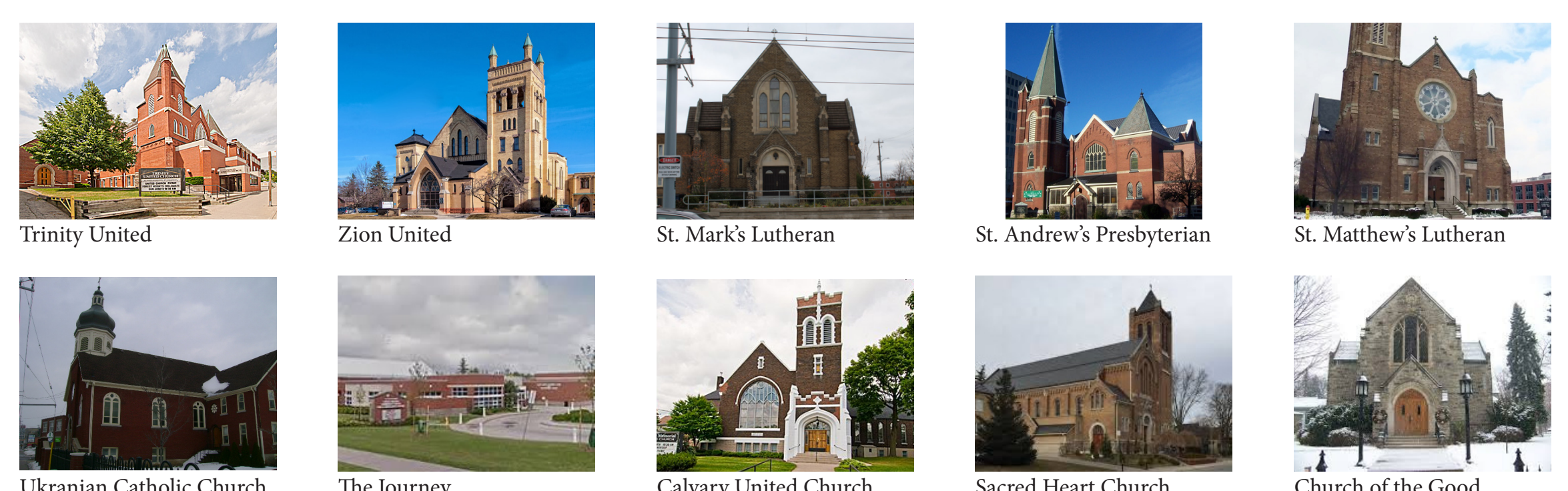

Ukranian Catholic Church

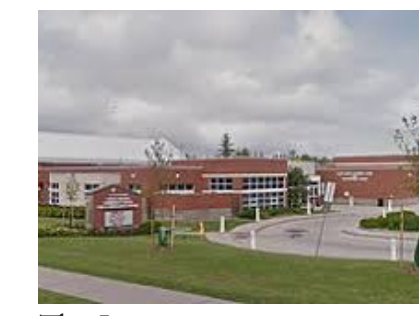

The Journey

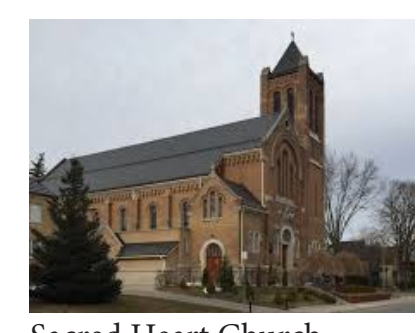

Sacred Heart Church

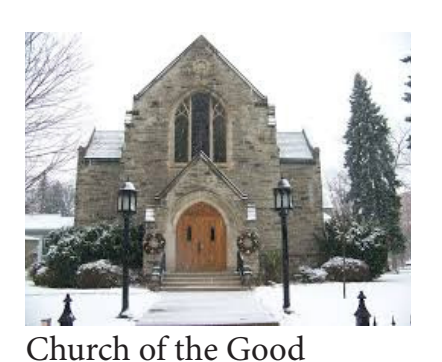

Church of the Good
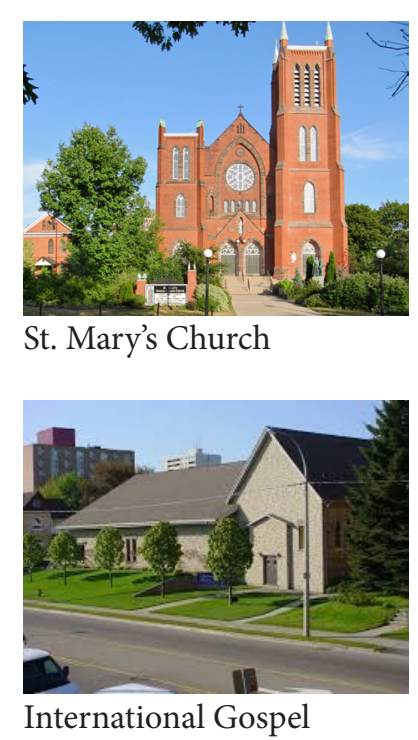

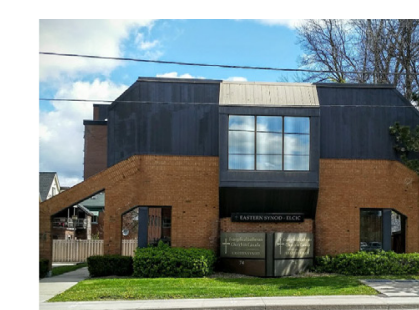

Eastern Synod Evangelical Church of Canada

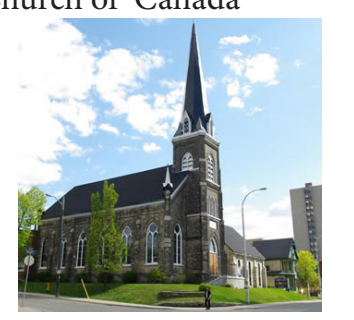

St. Paul's Lutheran Church

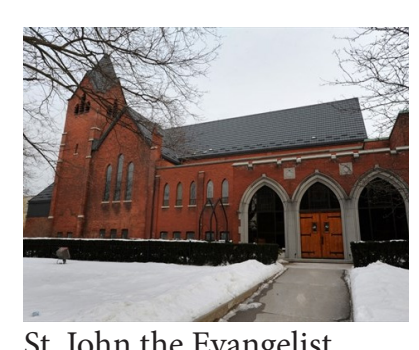

St. John the Evangelist

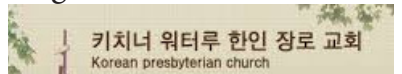

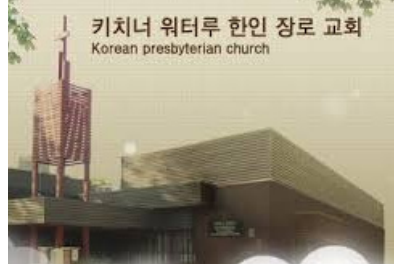

K-W Korean Presbyterian Church
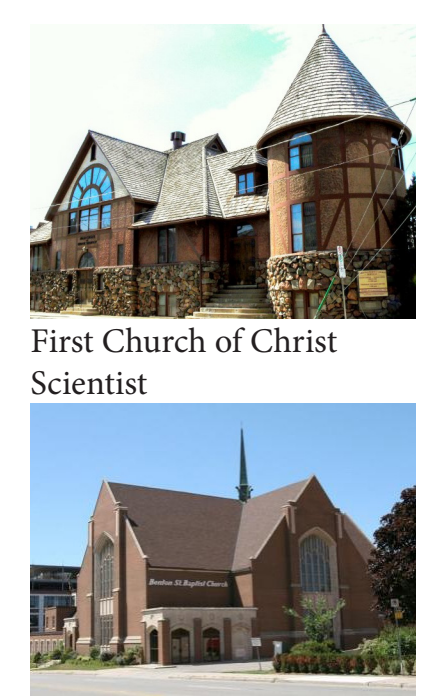

Benton Street Baptist

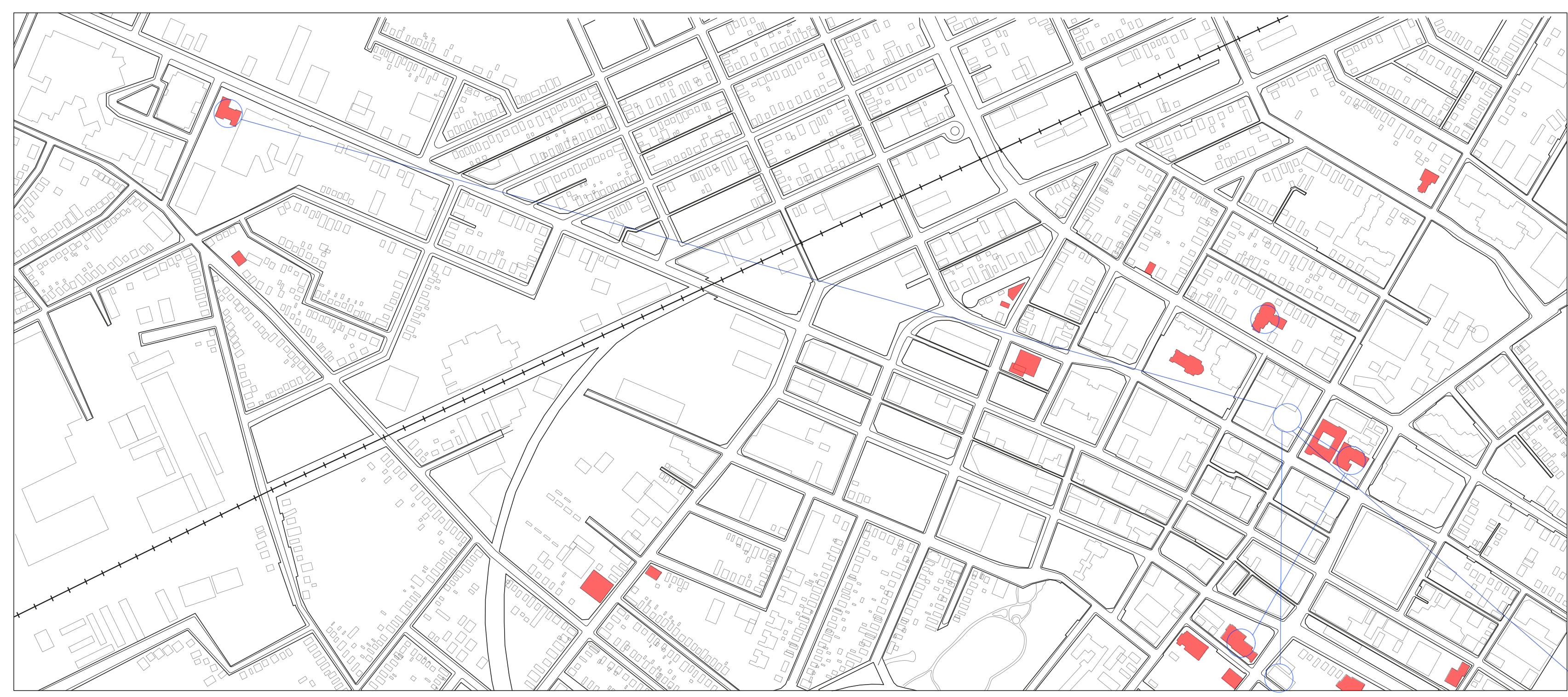

Trinity United Church

Zion United Church

St Mark's Lutheran Church

St. Andrew's Presbyterian Church

St Matthew's Lutheran Church

St Mary's Church

Eastern Synod Evangelical Church of Canada

St. John the Evangelist Anglican Church

First Church of Christ Scientist

Ukrainian Catholic Church of the Transfiguration

The Journey - A Christian Church

Calvary United Church

Sacred Heart Church

Church of the Good Shepherd

International Gospel Center

St Paul's Lutheran Church

K-W Korean Presbyterian Church

Benton Street Baptist Church

Religious Institutions in the Downtown Core

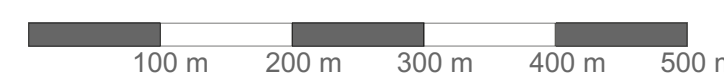







Synthesis

Trinity United

Proximity map showing the land use surrounding Trinity United.

Noteworthy:

- Facing the Kitchener Courthouse

- St. Peter's Lutheran Church directly behind Trinity United

- Surrounded by commercial and institutional land uses.

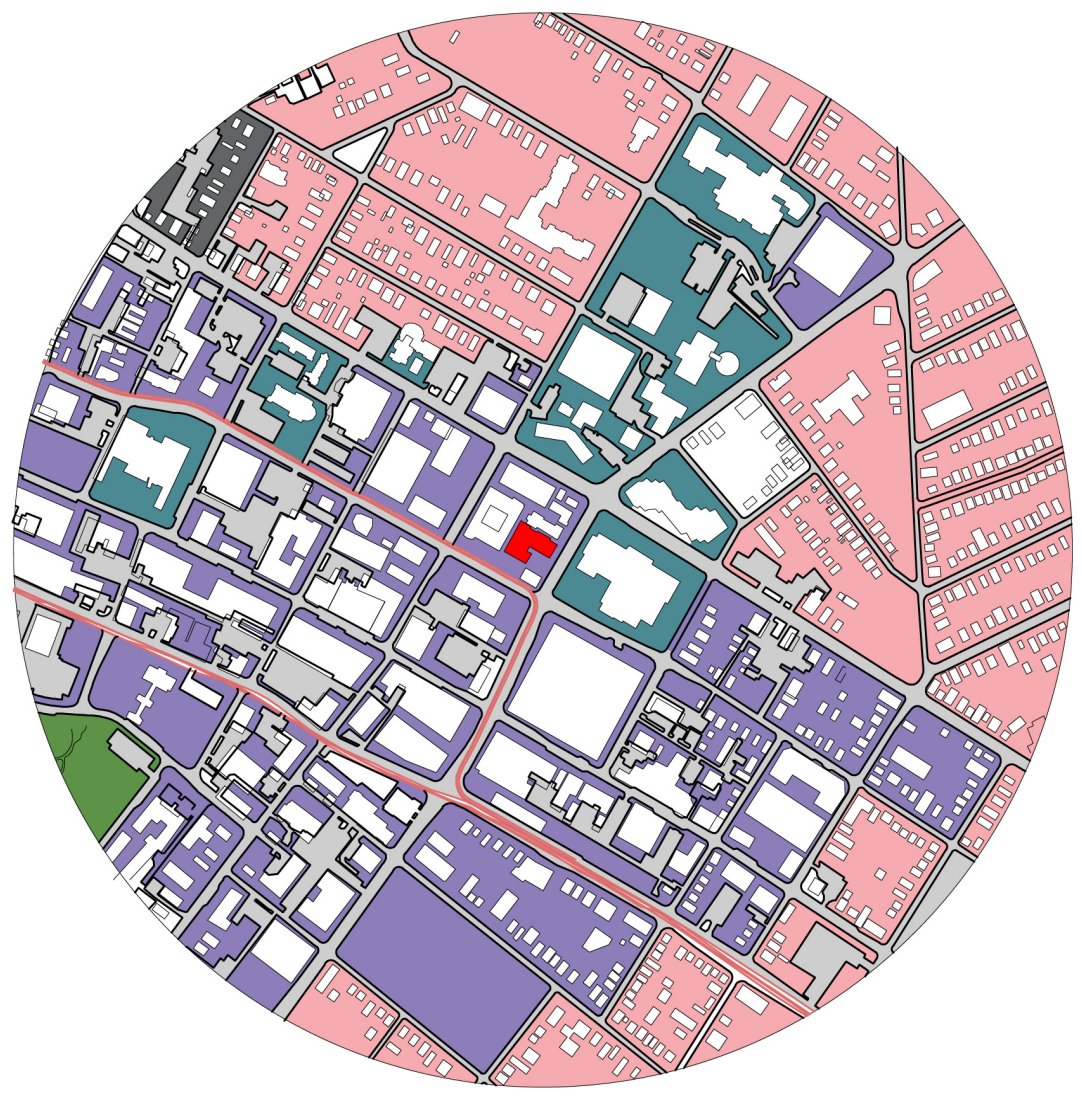


Synthesis

St. Mark's Lutheran

Proximity map showing the land use surrounding St. Mark's Lutheran

Noteworthy:

- Beside K-W Grand River Hospital and Kitchener Collegiate Institute

- Across the street from Mount Hope Cemetery, oldest cemetery in Kitchener Waterloo

- Residential areas closer to the church

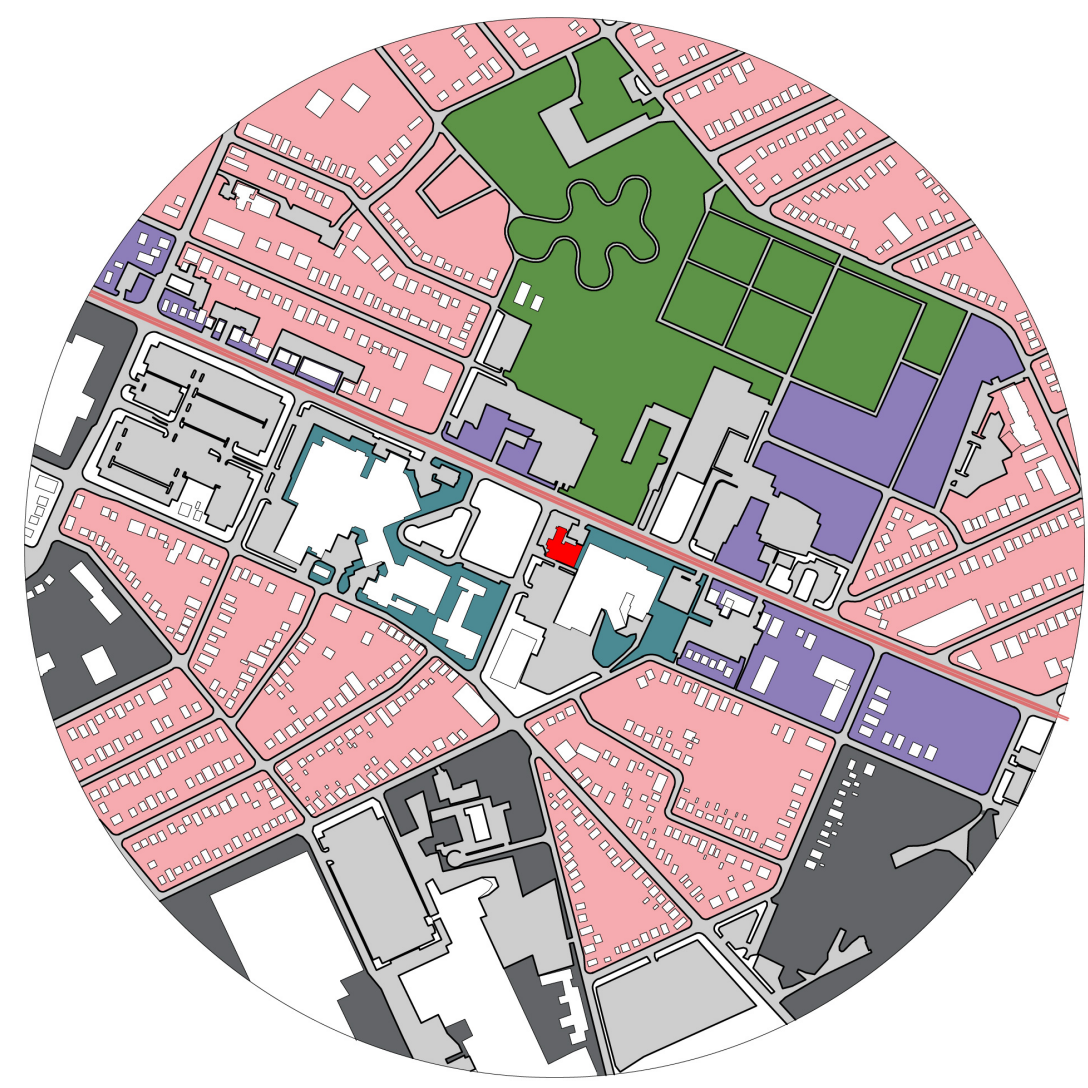


Synthesis

\section{Zion United}

Proximity map showing the land use surrounding Zion United

Noteworthy:

- On the border of the commercial area and the residential areas

- Very little relation to surround buildings - small separated homes and single commercial buildings across the road

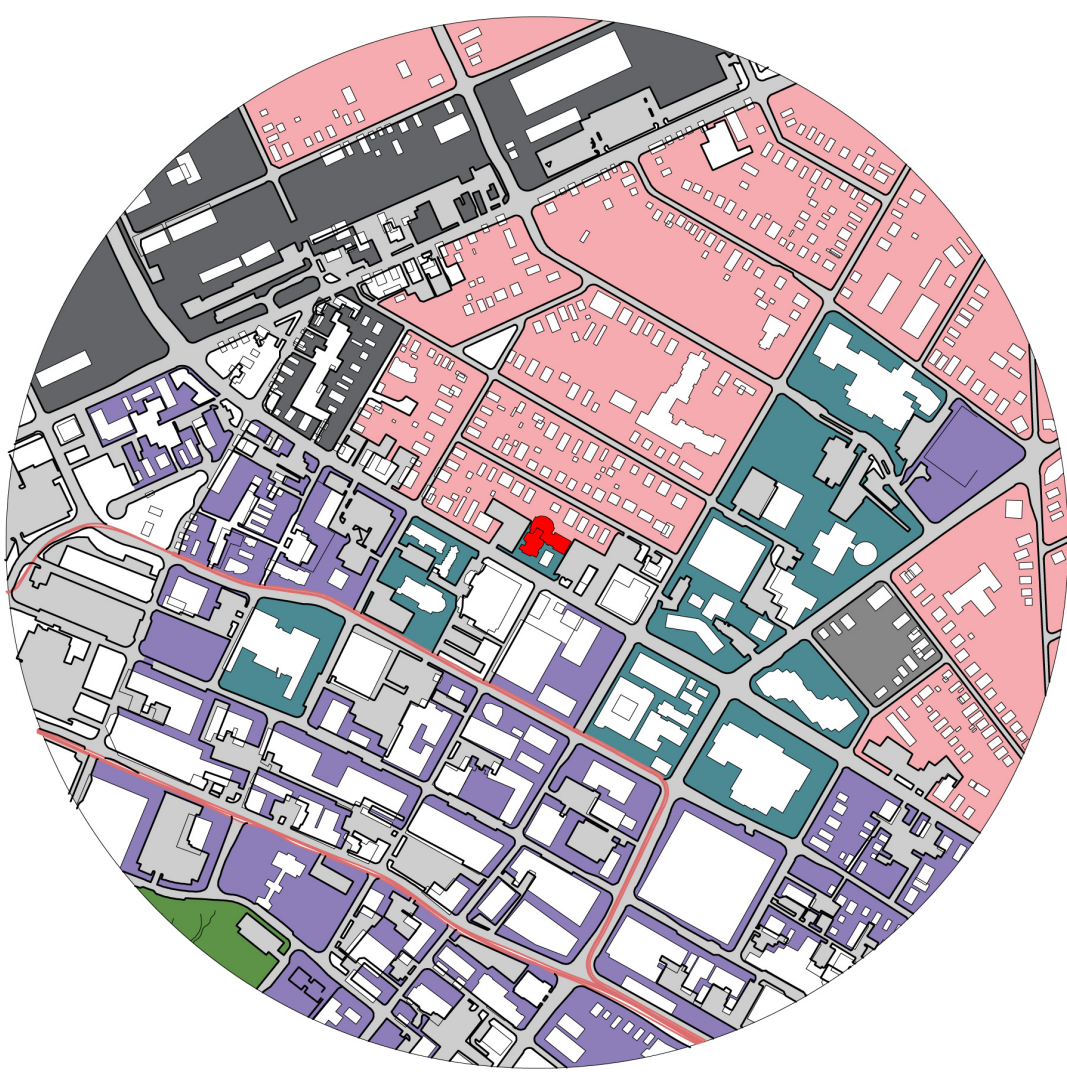




\section{Imagined Interventions}

\section{Trinity United}

The proposed intervention would take place while the building was being demolished. The front facade would be removed as well as the vestibule addition and the two towers. In the sanctuary a set of theater set flying rigs would be installed transforming it into a temporary open air theater. This theater would face the court house and its large plaza.

There are several connections to make between the building's original use as a church, the congregation it housed and the temporary theater installation. The first is the relationship both a theater and a church service have with an audience. During a church service there are specific moments where the congregation is very clearly the audience, for example during the sermon. They are listening to what is being taught and receiving the pastor's message. During worship the dynamic between the congregation and the individuals leading them is not of a performer and an audience. The aspiration of worship leaders is to guide the entire congregation in joining them in the collective experience of worship. In other words the congregation's role fluctuates between audience and performer. In the open air theater there is potential for the audience to engage in such a way that they become performers themselves. There is also the opportunity to immerse oneself by sitting in the church's mezzanine between the set pieces practically on the stage.

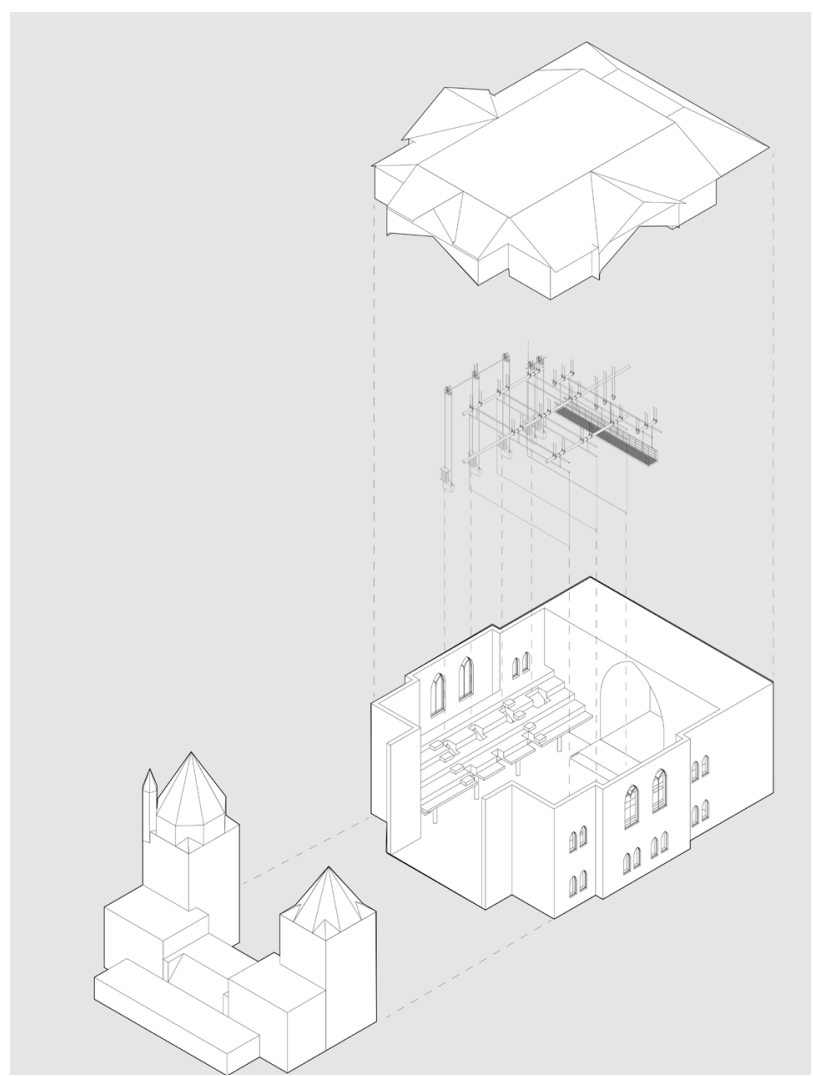


Imagined Interventions

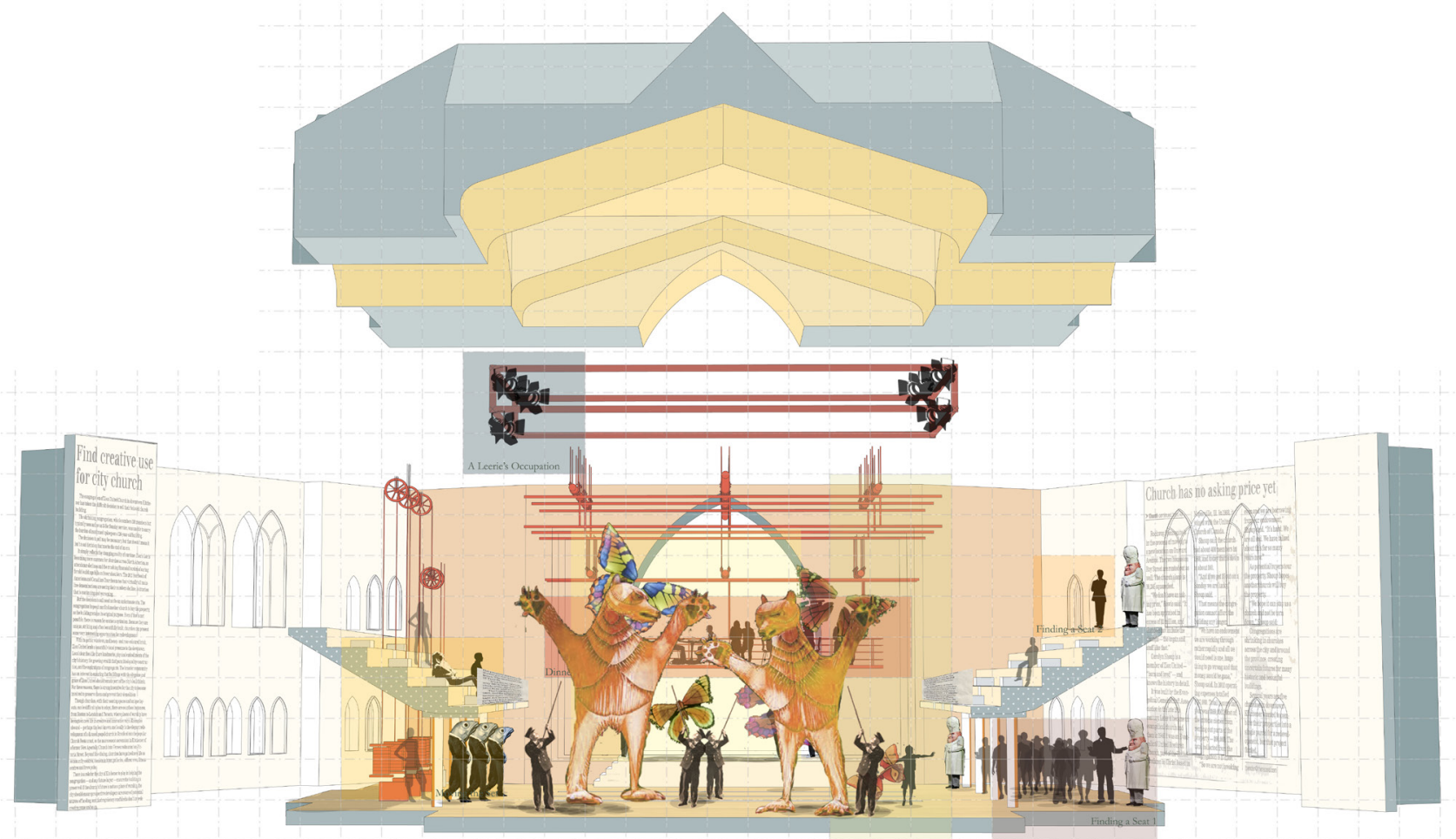




\section{Imagined Interventions}

The second connections goes back to the Character Defining Elements discussed in Document Two. The congregation at Trinity United throughout the years gave added value to intellectual pursuits, part of that being the exchange of ideas and the participation in current issues. A theater could act as a platform to share points of view, expose problems and discuss issues.
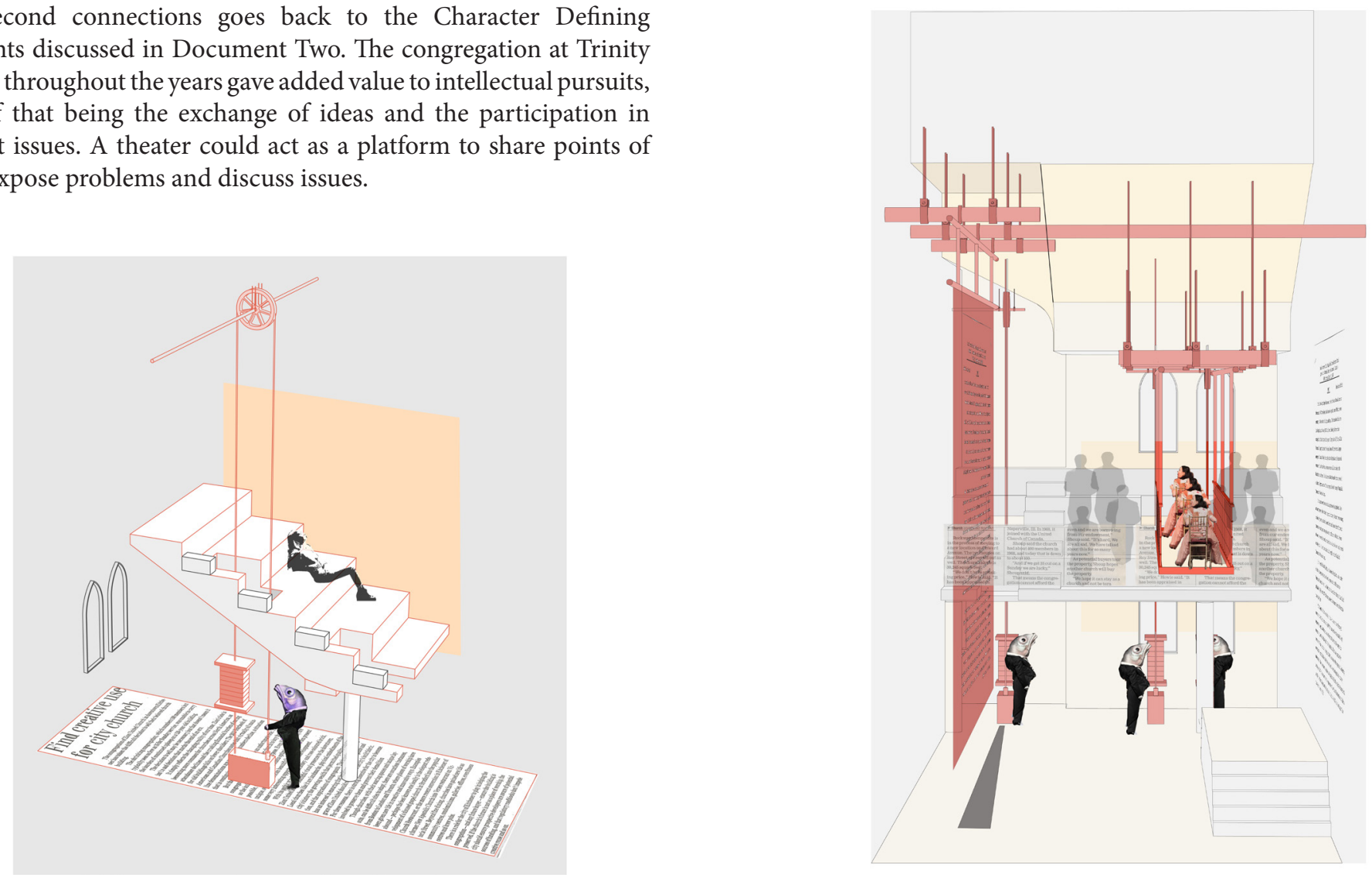


\section{Imagined Interventions}

\section{St Mark's Lutheran}

The proposed intervention for St. Mark's Lutheran would be a community garden between the Sanctuary and the Parish Hall. The office spaces and hallways between the two gathering spaces would be removed and replaced by a community vegetable garden.

The main connection between the intervention and the church building stems from the congregation's community outreach missions, specifically their potluck dinners. This intervention would allow the congregation the facilities to continue their tradition as well as a place to grow produce for their meals. The garden has a central tree mostly to provide shade but also as a reminder of the sites' previous religious use. There are many Christian metaphors and parables that use trees to illustrate teachings. Around the tree are radially arranged planters reminiscent of a contemplative labyrinth. The space is meant to be functional but also beautiful.

The preservation of the gathering spaces is site specific. The highschool and hospital adjacent to the church and the cemetery across the street could benefit from access to a gathering spaces that are equipped with contemplative areas and a kitchen.

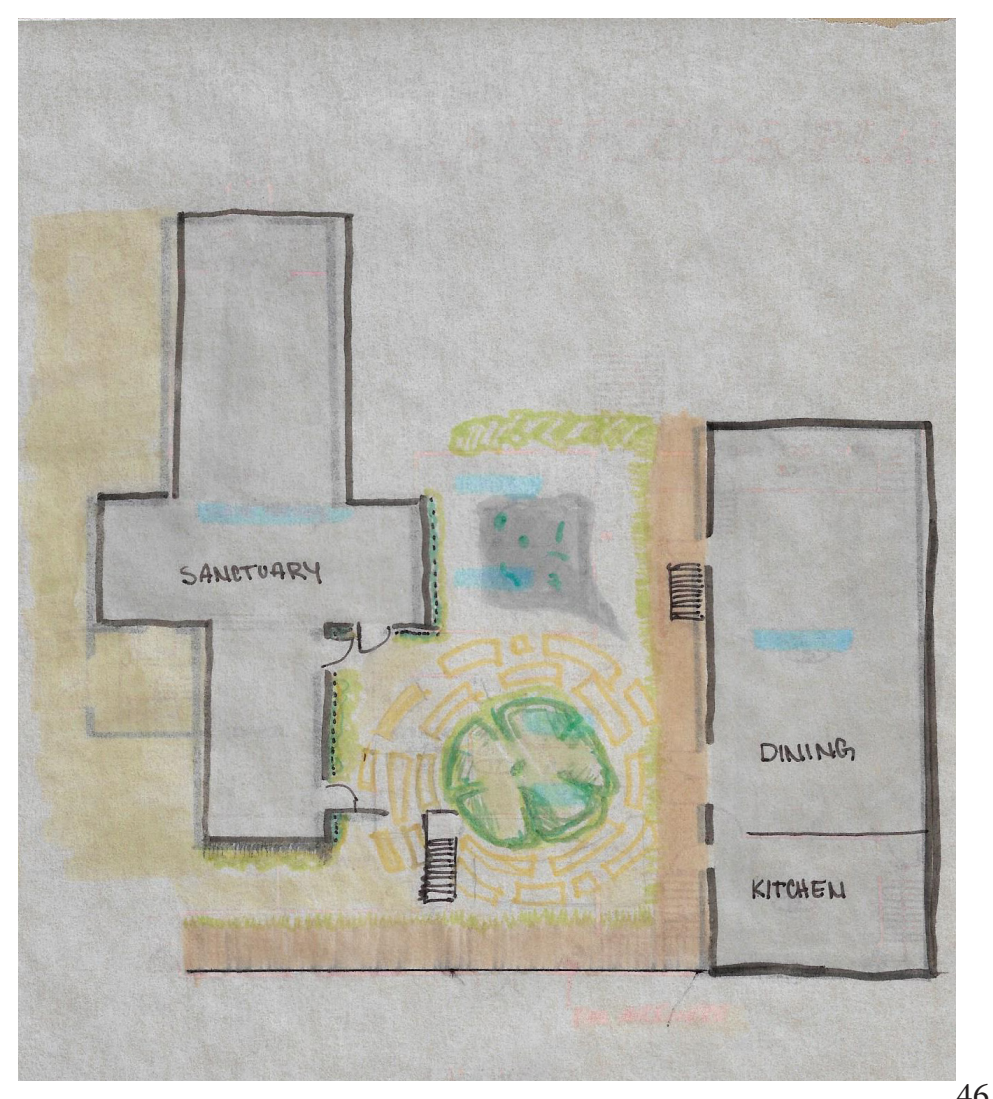


Imagined Interventions

St Mark's Lutheran

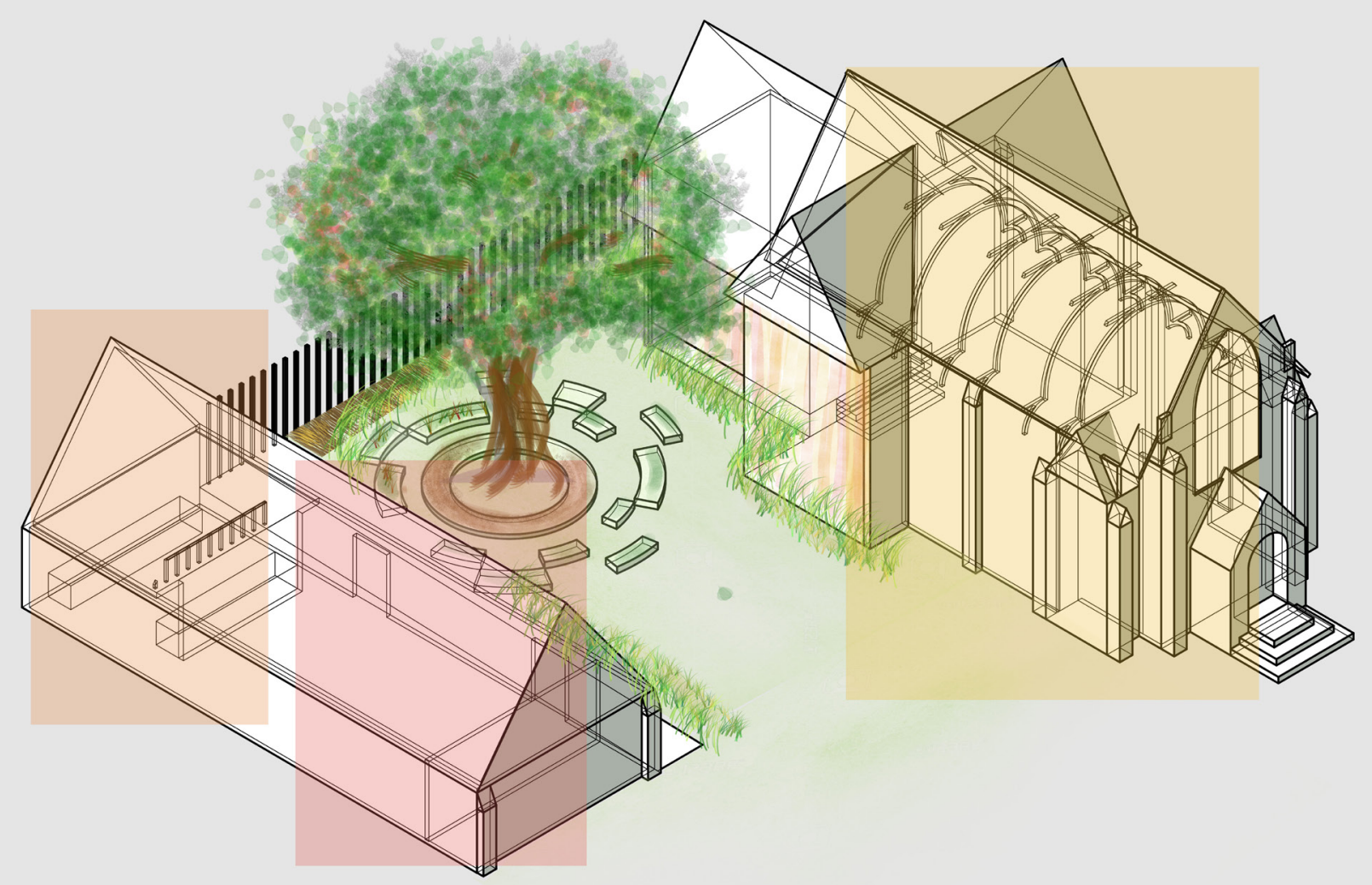




\section{Imagined Interventions}

\section{Zion United}

The proposed intervention for Zion United would see the building transformed into place for music and healing. The round Sunday School room would be subdivided into individual spaces for therapy, meditation and relaxation. The Sanctuary would become an area for music and movement or dance. This intervention connects to the Character Defining Elements that was discussed in Document Two.

The congregation's recollections revolve around the strong musical tradition at Zion United. This intervention is meant to emphasize and expand the effects of participating in the production of music, listening to it or dancing along to it. Music can be very personal but it can also be a unifying factor for a group of people. In response to that duality there are spaces in which music, meditation and healing can be experienced privately and in a group setting.

Due to the lack of access to the inside of the building there is a section between the Sanctuary and Round room without documentation. This interstitial space was imagined as a transition between the group activities to the individual spaces.

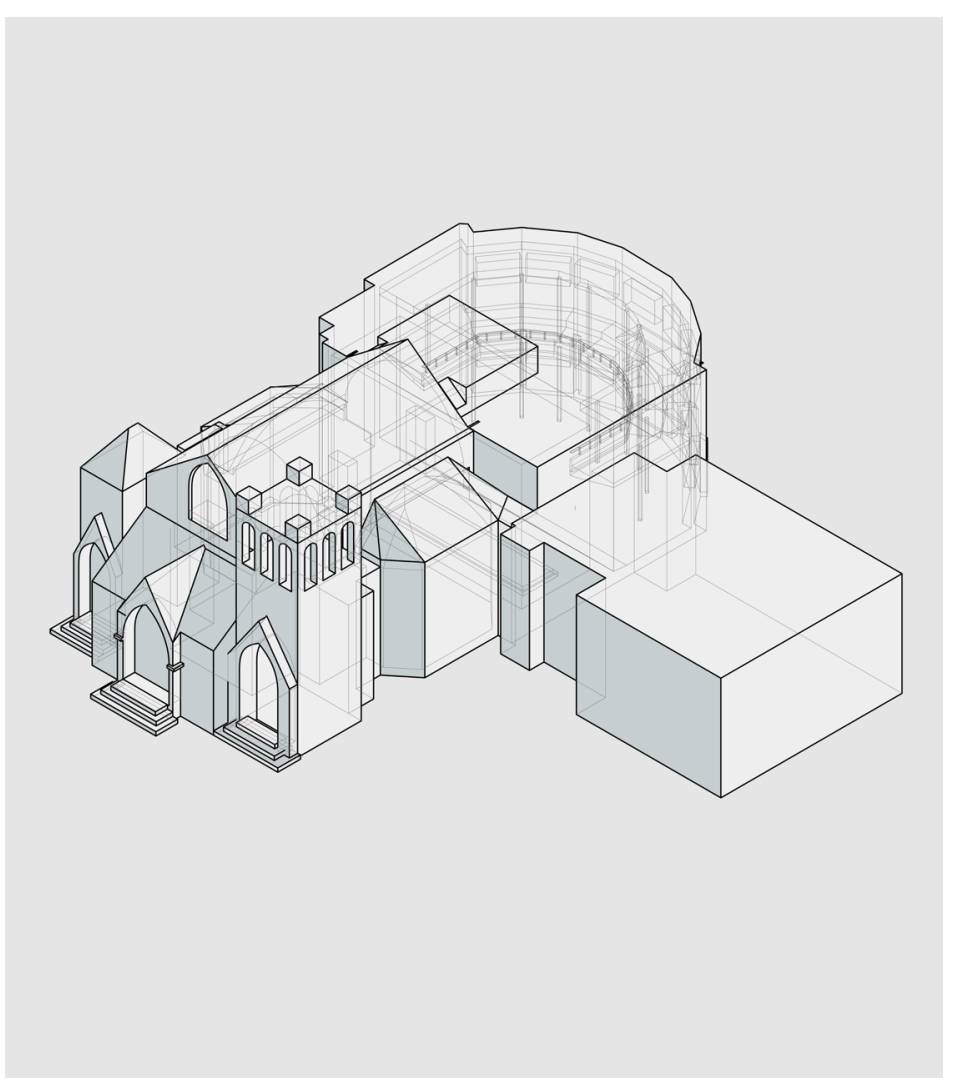




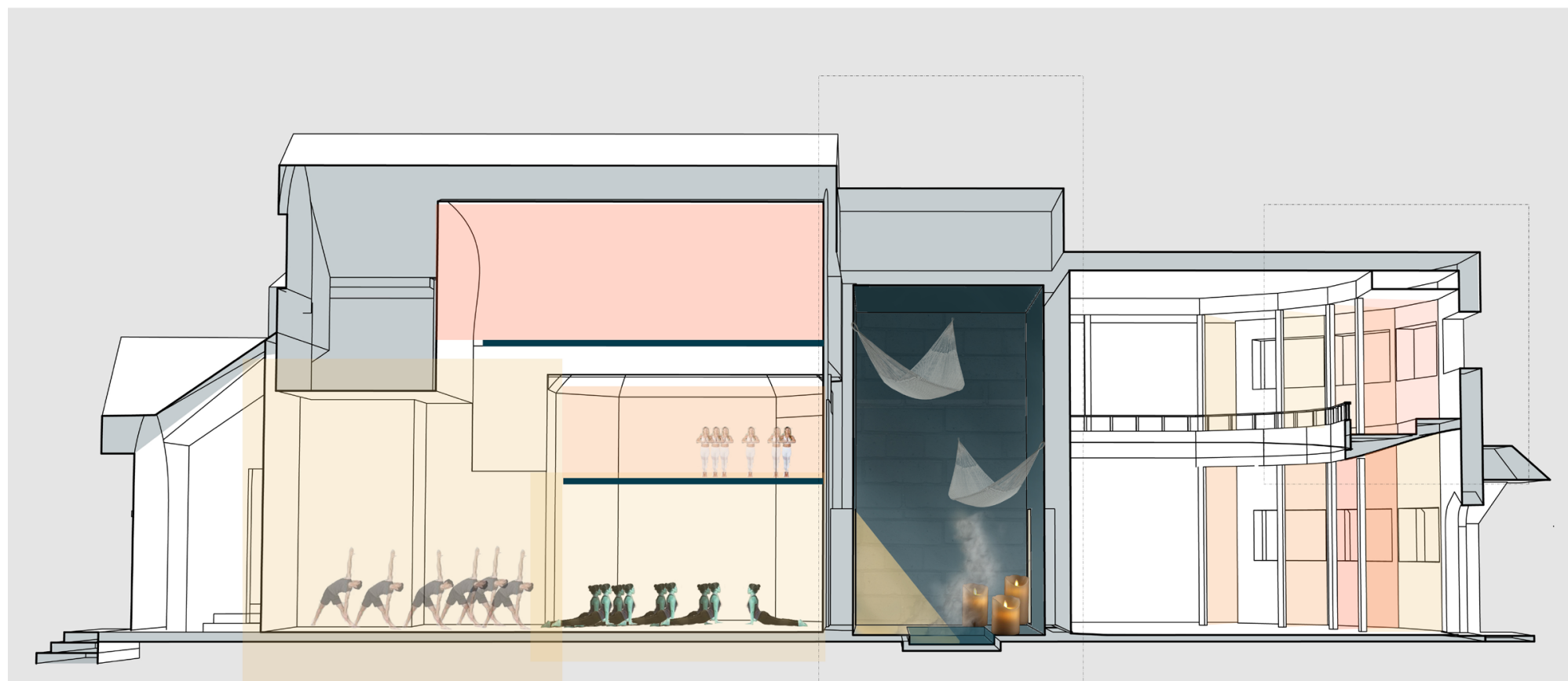




\section{Post Script}

Throughout the development of this thesis one question repeatedly made an appearance in the discussions. If the physical aspects of the building were not to be privileged or taken in consideration should the churches remain at all?

During the early stages of this project a potential site was identified outside of Kitchener where a church was demolished because the roof was about to collapse. The congregation was able to rebuild on the adjacent lot but the original site of the church remained empty. This thesis began with a very strong intention to work with existing abandoned buildings and the site was not considered to be appropriate for this investigation. However the further the intangible Character Defining Elements were discussed and defined the more relevant became this question of if the physical elements were necessary at all.

Views on religion are changing. Perhaps the church buildings are not necessary to preserve some of the memories and traditions of what went on within their walls. For the time being this thesis aims to begin to experiment with intangible elements as the primary focus in the adaptive reuse of abandoned churches.

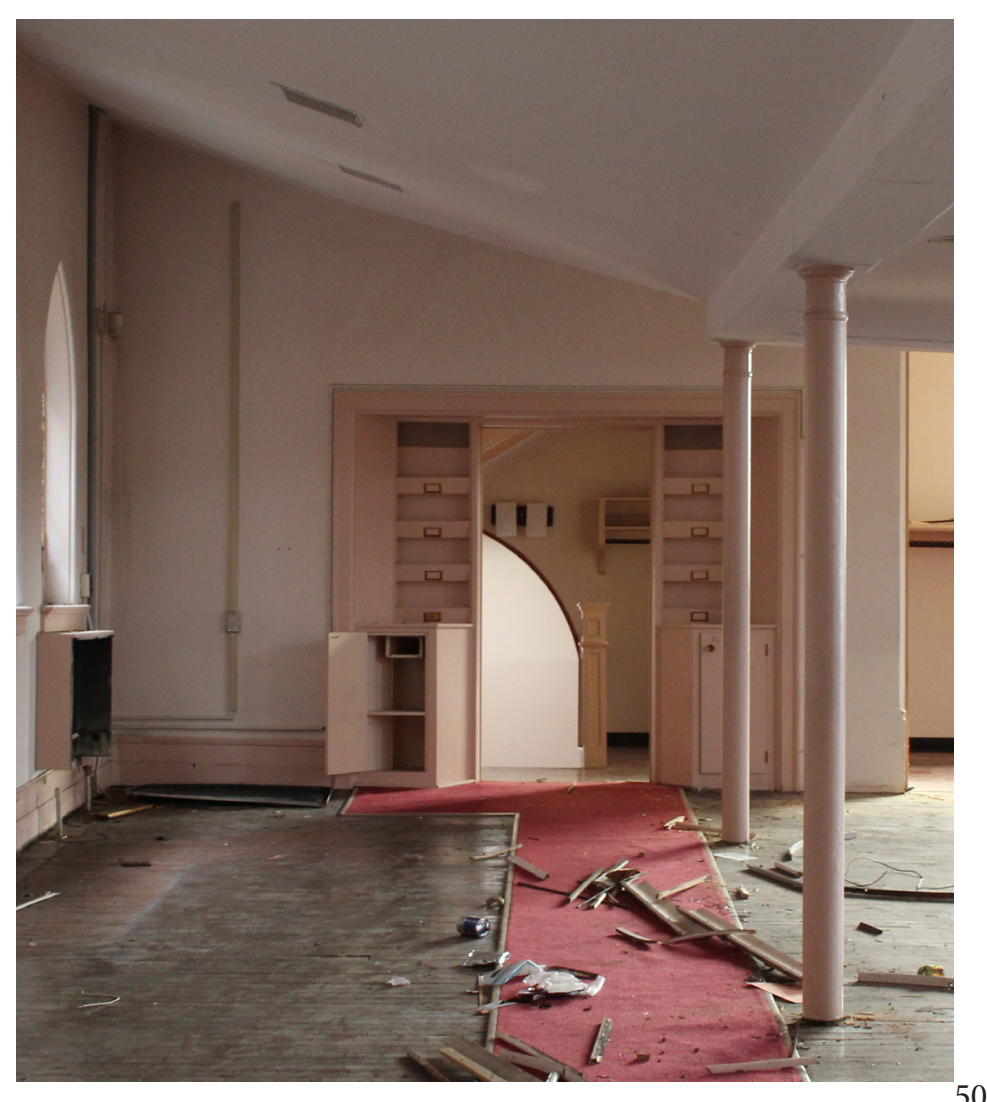




\section{Appendix A}

The blue lines illustrate the movement of the congregations throughout their history. St. Mark's Lutheran began as th First English Lutheran church and Trinity United began as Trinity methodist. Both have had a close relationship with St Matthews Lutheran. At one point they bought Trinity's building and St. Mark's later bought it off of them. There is an intrinsic sense of connectivity between the sites. At the moment I am missing a lot of information on Zion United, I am meeting someone who has this information in the coming weeks.

Township Hall,

74 Frederick Street

Trinity United, $1875-1905$ Trinity United, $1905-2017$ Concordia Hall

First English Lutheran, 1913 - 1938 First English Lutheran, 1913

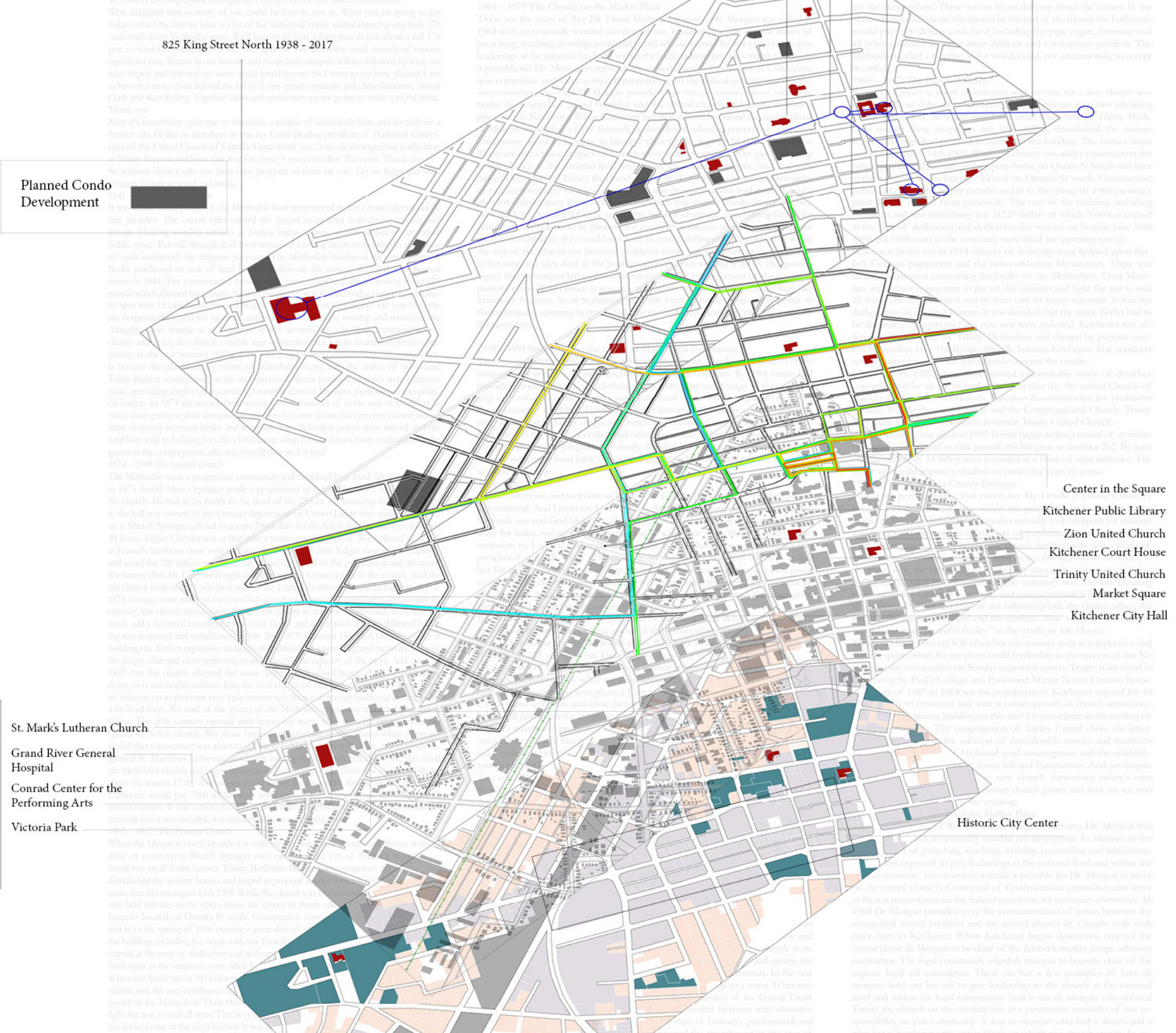

Here we can see how far the residential area has been pushed out of the downtown core. The development plans reintroduce dwellings in the form of mid to high rise condos catered to young professionals. On the site of Trinity United a $25+$ story condo building is being built.

At the level of public transportation the 3 sites are well connected and form a circuit. Their proximity suggests a network between the 3 of the churches and their connectivity supports that.

Apart from the 3 sites there are 15 other Christian churches in the will bring an i f remains to be seen if the new strategy of densification demographic encouraged to move to Kitchener is precisely the one with the highest unaffiliation statistic. 


\section{Appendix A}

\section{Typical Service}

A very simple itinerary for a Sunday would show that a service would open with worship where everyone participates in singing hymns, songs, psalms or any combination of the three. Offering/tithing usually follows with a small message attached. Many churches take the opportunity to give announcements of the events and happenings for the week immediately after taking up the offerings or even during its collection. Now a days churches dismiss the children and they go off to their respective Sunday School classes while the adults stay for the sermon. It was common 50 years ago or so for everyone to listen to the sermon and then everyone went to a Sunday School class, adults included. After all preaching and Sunday school has concluded people are free to go home, at this time it is very common for groups to spontaneously form to eat together or to socialize. 
Brecheter, Christopher. Abandoned Potential. Ottawa, Ontario: Carleton University, 2011.

Butterworth, Carolyn, and Sam Vardy. "Site-Seeing: Constructing the 'Creative Survey"' Field: A Free Journal for Architecture 2 (November 2013): 125-38.

Bloziers, Charles. Old Buildings, New Designs: Architectural Transformations. New York, NY: Princeton Architectural Press, 2012.

Clarke, Brian; Macdonald, Stuart. Leaving Christianity: Changing allegiances in Canada since 1945. McGill-Queen's University Press, 2017

Conforti, Amanda. Towards a Second Reading of Site: Reinterpreting Heritage Recording and Information. Ottawa, Ontario: Carleton University, 2011.

Giles, Richard. Re-Pitching the Tent: Re-ordering the Church for Worship and Mission. 3rd ed. Norfolk, UK: Canterbury Press, 2004.

Magrill, Barry. A commerce of Taste: Church architecture in Canada, 1867 - 1914. McGill-Queen's University Press. Montreal. 2012

Preiss, Anna. Prognostic Architecture: An Alternative to Heritage
Conservation. Ottawa, Ontario: Carleton University, 2011.

Pryse, Michael, Bishop. "Salt \& Light." Speech, 100th Anniversary Message, St. Mark's Lutheran Church, Kitchener, November 07, 2018.

Richardson, Douglas Scott, John De Visser, and Peter Richardson. Canadian Churches: An Architectural History. Richmond Hill, ON: Firefly Books, 2007.

"St. Marks Lutheran Church." St Marks Lutheran Church RSS. Accessed December 12, 2018. https://stmarkskw.org/servingothers/.

Taylor, Richard. How to Read a Church: A Guide to Images, Symbols, and Meanings in Churches and Cathedrals. Mahawh, NJ: Hidden Spring, 2005.

Uffelen, Chris Van. Re-use Architecture. Salenstein: Braun, 2011.

Wong, Liliane. Adaptive Reuse: Extending the Lives of Buildings. Basel: Birkhäuser, 2017.

Zion Evangelical Church. 100th Anniversary 1839 - 1939. Waterloo, ON: Chronicle Press, 2011. 